\title{
Mathematical analysis of a generalized epidemic model with nonlinear incidence function
}

\author{
O. M. Ogunmiloro ${ }^{*}$ and H. Kareem
}

\begin{abstract}
Background: Though different forms of control measures have been deployed to curtail disease transmission, which are mostly through vaccination, treatment, isolation, etc., using mathematical models. Therefore, there is a need to consider the strict compliance or attendance of human individuals to medical awareness program through media outlets like radio, television, etc. In this work, a generalized mathematical model of two groups of infectious individuals who are compliant and non-compliant to medical awareness program is studied.

Results: A generalized Susceptible-Exposed-Infected-Recovered (SEIR) model with two groups of infectious individuals who attend or are compliant and those who do not attend or are non-compliant to medical awareness program is established. The analytical results of the model shows that the model is positive, well-posed, and epidemiologically reasonable. The two equilibria and the basic reproduction number $R_{r}$ of the model is computed and analyzed and it is shown that the disease-free equilibrium is locally and globally asymptotically stable when $R_{\mathrm{r}}<1$ and the endemic equilibrium is globally stable when $R_{r}>1$. Simulations are carried out by varying some parameters when $R_{\mathrm{r}}$ is less and above unity. The simulations suggest that control interventions are to be implemented and medical awareness program scaled up to mitigate the spread of diseases. Furthermore, two numerical methods of Runge-Kutta and Differential Transform Method (DTM) are employed to obtain the approximate solutions of the model system equations, and it is observed that the results of the two methods agreeably compare with each other in terms of efficiency and convergence.

Conclusion: This work should be taken into consideration by health policy makers and bio-mathematicians, because existing literature only take into consideration, how diseases spread and its management without considering the impact of strict compliance to consistent awareness program to mitigate the spread of diseases, which has been considered in this work. The limitation of this work is the unavailability of data on individuals in disease endemic regions who always and who do not comply with medical awareness programs.
\end{abstract}

Keywords: Susceptible, Reproduction number $R_{r}$, Local stability, Global stability, Incidence function

\section{Background}

Mathematical models are important techniques that have been greatly explored to describe the transmission dynamics of evolving and re-evolving diseases in epidemiology. The essence of epidemic models is to understand, prepare for future occurrence of epidemic

\footnotetext{
*Correspondence: oluwatayo.ogunmiloro@eksu.edu.ng; omoalhaji97@yahoo.com

Department of Mathematics, Ekiti State University, Ado-Ekiti, Nigeria
}

breakout, and to implement necessary intervention strategies to curtail the spread of diseases in human and environment host population. One of the earliest publications on mathematical models of infectious disease are the works of [1-3]. The authors discussed on the division of the human host population into compartments and epidemic interactions between them. Also, several mathematical techniques have been employed by authors to quantitatively and qualitatively describe the dynamics

\section{Springer Open}

(c) The Author(s). 2021 Open Access This article is licensed under a Creative Commons Attribution 4.0 International License, which permits use, sharing, adaptation, distribution and reproduction in any medium or format, as long as you give appropriate credit to the original author(s) and the source, provide a link to the Creative Commons licence, and indicate if changes were made. The images or other third party material in this article are included in the article's Creative Commons licence, unless indicated otherwise in a credit line to the material. If material is not included in the article's Creative Commons licence and your intended use is not permitted by statutory regulation or exceeds the permitted use, you will need to obtain permission directly from the copyright holder. To view a copy of this licence, visit http://creativecommons.org/licenses/by/4.0/. 
of models of many diseases like onchocerciasis [4, 5], conjunctivitis [6], co-infection of malaria with filariasis and toxoplasmosis $[7,8]$, as well as using stability theorems and optimal control analysis to qualitatively and quantitatively analyse epidemic models [9-11]. Medical awareness programs through media outlets like radio, electronic prints, television, and social media are means of communicating to the human host community to be aware of how to mitigate disease spread and forestall healthy living $[12,13]$. The basic reproduction number $R_{r}$ is an epidemic threshold used to determine the number of secondary cases of infections arising as a result of an introduction of an infected individual into a susceptible host population during his or her period of infection. $R_{r}$ have been used immensely to describe the reproductive rate of many diseases [14]. Also, [15] worked on the analysis of an SEIR epidemic model with saturated incidence and saturated treatment functions, while [16] investigated the impact of vaccination strategies for a SISV epidemic model guaranteeing the nonexistence of endemic solutions. In addition, [17] worked on the SEIR model formulation and compartmental epidemic interactions in the human population, while [18] worked on assessing the inference of the basic reproduction number $R_{r}$ in SIR model incorporating growth scaling parameter, see also [19, 20]. Other works on SEIR modeling includes [21-24], while the publications of $[25,26]$ proved useful to this study by employing the use of Lyapunov functions to analyze model stability domain. Numerical methods of Runge-Kutta and DTM have proved useful in obtaining the convergent approximate solutions of epidemic models, see [27, 28]. In view of the cited publications, we consider the SEIR epidemic model with two groups of infected individuals who attend or are compliant to medical awareness program and those who did not attend or are noncompliant to medical awareness program, with saturated incidence function. Section 2 discusses the positivity and invariant region analysis of the model, while the equilibria of the model and basic reproduction number $R_{r}$ is obtained. Section 3 involves the local and global stability of model system at the disease-free and endemic equilibrium solutions. Furthermore, we employ the DTM and Runge-Kutta fourth-order method to obtain the approximate solutions of the model. The results obtained agreeably compare with each other. Also, we performed simulations involving some parameters of the model when $R_{r}<1$ and $R_{r}>1$.

\section{Model establishment and analytical results}

The total human host population denoted $N(t)$, at time $t>0$ is classified into five compartments of susceptible denoted $S(t)$, which are the individuals who are at risk of acquiring the disease. Also, people who have been latently infected but are not yet infectious are denoted by $E(t)$, symptomatic individuals who did not attend medical awareness program are denoted by $I_{u}(t)$, symptomatic individuals who did attend medical awareness program are denoted by $I_{\nu}(t)$, and the recovered individuals are denoted by $R(t)$, so that

$$
N(t)=S(t)+E(t)+I_{u}(t)+I_{v}(t)+R(t) .
$$

The susceptible population is increased by the recruitment of individuals at the rate $A$, following an effective contact with infected individuals in the $I_{u}$ and $I_{v}$ compartment, the force of infection is denoted $\lambda(t)$, and described by the quantity

$$
\lambda(t)=\beta\left(\frac{\mathrm{I}_{\mathrm{u}}}{1+\phi_{1} \mathrm{I}_{\mathrm{u}}}+\frac{\theta \mathrm{I}_{\mathrm{v}}}{1+\phi_{2} \mathrm{I}_{\mathrm{v}}}\right) .
$$

In (2), $\lambda(t)$ is the force of infection that takes into account the high saturation of infected individuals in the human host community, where $\beta$ is the transmission rate of infection and $\theta$ is the modification parameter that takes into account the relative infectiousness of medical awareness non-compliant individuals to transmit infection at a higher rate than medical awareness compliant individuals. We adopt a nonlinear saturated incidence rate in the two groups of individuals to describe the behavioral change and crowding effect of infected humans where $\phi_{1}$ and $\phi_{2}$ measures the inhibitory effect. But if $\phi_{1}$ and $\phi_{2}$ are zeros, then the incidence function follows a bilinear incidence which is commonly adopted in many models. The population of the susceptible individuals is further decreased by natural death rate $\mu$. Thus, the rate of change of the susceptible population is given by

$$
\frac{d S}{d t}=A-(\mu+\lambda(t)) S
$$

The population of exposed individuals is increased by the force of infection $\lambda(t)$. The compartment is further on decreased by the development of clinical symptoms, natural death and the disease-induced mortality at the rate $\epsilon, \mu$ and $d$ respectively, so that

$$
\frac{d E}{d t}=\lambda(t) S-(\in+\mu+d) E
$$

The population of the symptomatic individuals who did not attend medical awareness program is increased at the rate $\epsilon$. It is decreased by natural recovery rate $\gamma_{o}$, the rate of emergence of new symptoms $\sigma$, natural death $\mu_{1}$, and disease-induced mortality rate $\alpha_{1}$. This is given by 


$$
\frac{d I_{u}}{d t}=\in E-\left(\gamma_{o}+\mu_{1}+\alpha_{1}+\sigma\right) I_{u}
$$

The population of infected individuals who attended medical awareness program is increased progressively at the rate $\sigma$. The compartment is decreased by recovery rate $\gamma_{1}$, natural death rate $\mu_{2}$, and disease-induced mortality $\alpha_{2}$. It is assumed that the disease-induced mortality rate of individuals who attended medical awareness program is low in comparison with infected individuals who did not attend medical awareness program, such that $\alpha_{2}<\alpha_{1}$. Hence, the rate of change of this population is given by

$$
\frac{d I_{v}}{d t}=\sigma I_{u}-\left(\mu_{2}+\gamma_{1}+\alpha_{2}\right) I_{v}
$$

Finally, the population of recovered individuals is generated by the recovery of individuals who attend and who did not attend medical awareness program at the rate $\gamma_{o}$ and $\gamma_{1}$, while it is decreased by natural death rate $\mu$, so that

$$
\frac{d R}{d t}=\gamma_{o} I_{u}+\gamma_{1} I_{v}-\mu \mathrm{R}
$$

Thus, the model for the transmission dynamics of a generalized infectious disease with non-linear incidence of two groups of infected individuals who attend and did not attend medical awareness follows a first order system of ordinary differential equations given by

$$
\begin{aligned}
& \frac{d S}{d t}=A-(\mu+\lambda(\mathrm{t})) S, \\
& \frac{d E}{d t}=\lambda(t) S-(\epsilon+\mu+d) E, \\
& \frac{d I_{u}}{d t}=\epsilon E-\left(\gamma_{o}+\mu_{1}+\alpha_{1}+\sigma\right) I_{u}, \\
& \frac{d I_{v}}{d t}=\sigma I_{u}-\left(\mu_{2}+\gamma_{1}+\alpha_{2}\right) I_{v}, \\
& \frac{d R}{d t}=\gamma_{o} I_{u}+\gamma_{1} I_{v}-\mu R .
\end{aligned}
$$

Subject to the initial conditions $S(0)=S_{o}, E(0)=E_{o}$, $I_{u}(0)=I_{u o}, I_{v}(0)=I_{v o}, R(0)=R_{o}$.

\subsection{Positivity of the model}

It is assumed that the initial conditions of the model are non-negative and it is necessary to show that the solution of the model is positive.

Theorem 1: Let $\Omega=\left\{\left(S, E, I_{u}, I_{v}, R\right) \in R_{+}{ }^{5}: S_{o}>0, E_{o}>\right.$ $\left.0, I_{u o}>0, I_{v o}>0, R_{o}>0\right\}$. Then the solutions of $S, E, I_{u}, I_{v}$, $R$ are positive for $\mathrm{t} \geq 0$.

Proof: From the model system of differential Eq. (8), considering the first state equation given by

$$
\begin{aligned}
& \frac{\mathrm{d} S}{\mathrm{dt}}=\mathrm{A}-(\mu+\lambda) \mathrm{S}, \\
& \text { so that } \\
& \frac{\mathrm{d}(\mathrm{t})}{\mathrm{dt}} \geq(\mu+\lambda) \mathrm{S}, \\
& \frac{\mathrm{dS}(\mathrm{t})}{\mathrm{S}} \geq(\lambda+\mu) d t, \\
& \text { and } \\
& \int \frac{\mathrm{dS}(\mathrm{t})}{\mathrm{S}} \geq \int(\lambda+\mu) \mathrm{dt} .
\end{aligned}
$$

Solving (9) using separation of variable and applying the initial condition $S(0)=S_{o}$, yields

$$
S(t) \geq S_{o} e^{-(\lambda+\mu) t} \geq 0 .
$$

Also, from the second state equation of (8),

$$
\frac{d E}{d t}=\lambda S-(\epsilon+\mu+d) E .
$$

Simplifying (11) further yields

$$
\begin{aligned}
& \frac{d E}{d t} \geq(\epsilon+\mu+d) E \\
& \text { and } \\
& \int \frac{d E}{E} \geq \int(\epsilon+\mu+d) d t .
\end{aligned}
$$

On solving (12) using separation of variable and applying initial condition $E(0)=E_{o}$, yields

$$
E(t) \geq E_{o} e^{-(\epsilon+\mu+d) t} \geq 0
$$

From the third state equation in (8),

$$
\frac{d I_{u}}{d t}=\epsilon E(t)-\left(\gamma_{o}+\mu_{1}+\alpha_{1}+\sigma\right) I_{u},
$$

Simplifying (14) further become,

$$
\begin{gathered}
\frac{d I_{u}}{d t} \geq\left(\gamma_{o}+\mu_{1}+\alpha_{1}+\sigma\right) I_{u} \\
\text { and } \\
\int \frac{d I_{u}}{I_{u}} \geq \int\left(\gamma_{o}+\mu_{1}+\alpha_{1}+\sigma\right) d(t) .
\end{gathered}
$$

Solving (15) using separation of variable and applying initial condition $I_{u}(0)=I_{u o}$, yields

$$
I_{u}(t) \geq I_{u o} e^{-\left(\gamma_{o}+\mu_{1}+\alpha_{1}+\sigma\right) t} \geq 0 .
$$

In addition, taking the fourth state equation of (8),

$$
\frac{d I_{v}}{d t}=\sigma I_{u}(t)-\left(\mu_{2}+\gamma_{1}+\alpha_{2}\right) I_{v}
$$

where

$$
\int \frac{d I_{v}}{I_{v}} \geq-\int\left(\mu_{2}+\gamma_{1}+\alpha_{2}\right) d t .
$$


Solving (18) using separation of variable and applying initial condition $I_{v}(0)=I_{v o}$, yields

$$
I_{v}(t) \geq I_{v o} e^{-\left(\mu_{2}+\gamma_{1}+\alpha_{2}\right) t} \geq 0 .
$$

Finally, taking the fifth state equation of (8),

$$
\frac{d R}{d t}=\gamma_{o} I_{u}(t)+\gamma_{1} I_{v}(t)-\mu \mathrm{R} .
$$

The simplification of (20) yields

$$
\begin{aligned}
& \frac{d R}{d t} \geq-\mu \mathrm{R}, \\
& \text { and } \\
& \frac{d R}{R} \geq-\mu \mathrm{dt}, \\
& \int \frac{d R}{R} \geq-\int \mu \mathrm{dt} .
\end{aligned}
$$

Solving (21) using separation of variable and applying initial condition $R(0)=R_{o}$, yields

$$
R(t) \geq R_{o} e^{-\mu t} \geq 0 \text {. }
$$

From (10), (13), (16), (19), and (22), it is clear that at time $t>0$, the model solutions are positive.

This completes the proof of the theorem.

\subsection{Invariant region}

In this section, the model system is analyzed in an invariant region and shown to be bounded. The addition of the whole model system Eq. (8) yields

$$
\mathrm{N}=\mathrm{S}+\mathrm{E}+I_{u}+I_{v}+R,
$$

such that

$$
\frac{d N}{d t}=\frac{d S}{d t}+\frac{d E}{d t}+\frac{d I_{u}}{d t}+\frac{d I_{v}}{d t}+\frac{d R}{d t}
$$

and

$$
\frac{d N}{d t}=A-\mu N-d E-\alpha_{1} I_{u}-\alpha_{2} I_{v} .
$$

In the absence of natural and mortality due to disease, i.e., $\left(d=0, \alpha_{1}=0, \alpha_{2}=0\right)$, (25) becomes

$$
\frac{d N}{d t}=A-\mu N \text {. }
$$

Integrating both side of (26) yields

$$
\int \frac{d N}{A-\mu N} \leq \int \mathrm{dt}
$$

and

$$
\frac{1}{\mu} \ln (A-\mu N) \leq t .
$$

Simplification of (28) become

$$
\mathrm{A}-\mu N \geq e^{-\mu t} .
$$

Applying the initial condition, $N(0)=N_{o}$, (29) yields $A=A-\mu N_{o}$. Substituting $A=A-\mu N_{o}$ into (29) yields

$$
A-\mu N_{o} \geq\left(A-\mu N_{o}\right) e^{-\mu t} .
$$

Further simplification and re-arrangement of (30) yields

$$
N \leq\left(\frac{A}{\mu}-\frac{A-\mu \mathrm{N}_{\mathrm{o}}}{\mu}\right) e^{-\mu t} .
$$

As $t \rightarrow \infty$ in (31), the population size $N \rightarrow \frac{A}{\mu}$ implies that $0 \leq N \leq \frac{A}{\mu}$. Thus, the feasible solution set of the system equations of the model start and end in the region

$$
\Omega=\left(\left\{S, E, I_{u}, I_{\nu}, R\right\} \in R^{+5}: N \leq \frac{A}{\mu}\right) .
$$

Therefore, the basic model (8) is well posed mathematically and epidemiologically reasonable. Hence, it is sufficient to study the dynamics of the model system (8) in $\Omega$.

\subsection{Equilibria}

To find the disease-free equilibrium solutions, the righthand side of the model system (8) is equated to zero, evaluating it at when there is no disease in the system, i.e., $E=I_{u}=I_{v}=0$. Therefore, the disease-free equilibrium solutions are given by

$$
E_{o}=\left(S, E, I_{u}, I_{v}, R\right)=\left(\frac{A}{\mu}, 0,0,0,0\right) .
$$

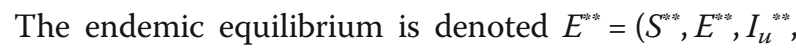
$\left.I_{v}^{* * *}, R^{* *}\right)$ and it occurs when a disease persist in the human host population. Therefore

$$
\begin{gathered}
E^{* *}=\left(S^{* *}, E^{* *}, I_{u}^{* *}, I_{v}^{* *}, R^{* *}\right)=\left(S^{*}=\frac{A}{\mathrm{~m}_{1}}, E^{*}=\frac{\lambda A}{\mathrm{~m}_{2} \mathrm{~m}_{3}}, I_{u}^{*}=\frac{\lambda \epsilon A}{\mathrm{~m}_{1} \mathrm{~m}_{2} \mathrm{~m}_{3}},\right. \\
\left.I_{v}^{*}=\frac{\lambda \sigma \epsilon A}{\mathrm{~m}_{1} \mathrm{~m}_{2} \mathrm{~m}_{3} \mathrm{~m}_{4}}, R^{*}=\frac{1}{\mu}\left[\frac{\lambda \epsilon \gamma_{o} A}{\mathrm{~m}_{1} \mathrm{~m}_{2} \mathrm{~m}_{3}}+\frac{\lambda \sigma \epsilon \gamma_{1} A}{\mathrm{~m}_{1} \mathrm{~m}_{2} \mathrm{~m}_{3} \mathrm{~m}_{4}}\right]\right) .
\end{gathered}
$$

Where $m_{1}=(\lambda+\mu), \quad m_{2}=(\epsilon+\mu+d), \quad m_{3}=\left(\gamma_{o}+\mu_{1}+\right.$ $\left.\alpha_{1}+\sigma\right), m_{4}=\left(\mu_{2}+\gamma_{1}+\alpha_{2}\right)$.

\subsection{Basic reproduction number $\left(R_{r}\right)$}

We want to show how the threshold that governs the spread of a disease, called the basic reproduction number is obtained.

Theorem 2.

Define $X_{s}=\left\{X=0 \mid X_{i}, i=1,2,3, \ldots\right\}$, in order to obtain $R_{r}$, new infections are distinguished from other changes in the populations. Such that, $F_{i}(x)$ is the rate of new 
manifestations of clinical symptoms in compartment $i$. Also, let $V_{i}^{+}$be the rate at which individuals move out of compartment $i$. Then $x_{i}=F_{i}(x)-V_{i}(x), i=1,2,3, \ldots$, and $V_{i}(x)=V_{i}^{-}-V_{i}^{+} . F$ is a non negative matrix and $V$ is a non-singular matrix.

Proof: We applied the next generation matrix method to the model equations starting with newly infective classes given by

$$
\left.\begin{array}{l}
\frac{d E}{d t}=\lambda(t) S-\mathrm{m}_{2} E \\
\frac{d I_{u}}{d t}=\varepsilon E-\mathrm{m}_{3} I_{u} \\
\frac{d I_{v}}{d t}=\sigma I_{\mathrm{u}}-\mathrm{m}_{4} I_{v}
\end{array}\right\}
$$

The rate of new clinical symptoms is given by

$$
\mathrm{F}=\left(\begin{array}{c}
\beta S\left(\frac{\mathrm{I}_{\mathrm{u}}}{1+\phi_{1} \mathrm{I}_{\mathrm{u}}}+\frac{\theta \mathrm{I}_{\mathrm{v}}}{1+\phi_{2} \mathrm{I}_{\mathrm{v}}}\right) \\
0 \\
0
\end{array}\right)
$$

And the rate of transfer terms of individuals is given by

$$
\mathrm{V}=\left(\begin{array}{c}
\mathrm{m}_{2} E \\
\epsilon E-\mathrm{m}_{3} I_{u} \\
\sigma I_{\mathrm{u}}-\mathrm{m}_{4} I_{v}
\end{array}\right)
$$

The Jacobian matrices of $F$ and $V$ evaluated at diseasefree equilibrium solution (33) are given by

$$
\mathrm{F}=\left(\begin{array}{ccc}
0 & 0 & \frac{\beta \mathrm{A}}{\mu} \\
0 & 0 & 0 \\
0 & 0 & 0
\end{array}\right)
$$

and

$$
V=\left(\begin{array}{ccc}
\mathrm{m}_{2} & 0 & 0 \\
\epsilon & \mathrm{m}_{3} & 0 \\
0 & \sigma & \mathrm{m}_{4}
\end{array}\right) .
$$

The inverse of $V$ is given by

$$
V^{-1}=\left(\begin{array}{ccc}
\frac{1}{\mathrm{~m}_{2}} & 0 & 0 \\
\frac{\epsilon}{\mathrm{m}_{2} \mathrm{~m}_{3}} & \frac{1}{\mathrm{~m}_{3}} & 0 \\
\frac{\epsilon \sigma}{\mathrm{m}_{2} \mathrm{~m}_{3} \mathrm{~m}_{4}} & \frac{\sigma}{\mathrm{m}_{4}} & \frac{1}{\mathrm{~m}_{4}}
\end{array}\right)
$$

and

$$
F V^{-1}=\left(\begin{array}{ccc}
\frac{\lambda A \epsilon \sigma}{\mu \mathrm{m}_{2} \mathrm{~m}_{3} \mathrm{~m}_{4}} & \frac{\lambda A \sigma}{\mu \mathrm{m}_{3} \mathrm{~m}_{4}} & \frac{\lambda A}{\mu \mathrm{m}_{4}} \\
0 & 0 & 0 \\
0 & 0 & 0
\end{array}\right)
$$

The eigenvalues of $F V^{-1}$ in (41) are given by

$$
\begin{aligned}
& \lambda_{1}=\lambda_{2}=0 \\
& \text { and } \\
& \lambda_{3}=\frac{\lambda A \in \sigma}{\mu \mathrm{m}_{2} \mathrm{~m}_{3} \mathrm{~m}_{4}} .
\end{aligned}
$$

The dominant eigenvalue in (42) is $\lambda_{3}$. Therefore, the basic reproduction number $R_{r}$ is given by

$$
R_{r}=\frac{\lambda A \epsilon \sigma}{\mu \mathrm{m}_{2} \mathrm{~m}_{3} \mathrm{~m}_{4}} .
$$

The threshold in (43) measures the rate at which new cases of infection arises, when a typical infected individual is introduced into a susceptible population of humans during their course of infection.

3 Stability analysis of the model system equilibria 3.1 Local stability of the disease-free equilibrium

Theorem 2: The disease-free equilibrium solution $E_{o}$ (33) is locally asymptotically stable if $R_{r}<1$.

Proof: The Jacobian matrix of system (8) at the disease-free equilibrium solution $E_{o}$ of (33) is given by

$$
J\left(E_{o}\right)=\left(\begin{array}{ccccc}
-\mathrm{m}_{1} & 0 & 0 & 0 & 0 \\
\lambda & -\mathrm{m}_{2} & 0 & 0 & 0 \\
0 & \varepsilon_{0} & -\mathrm{m}_{3} & 0 & 0 \\
0 & 0 & \sigma & -\mathrm{m}_{4} & 0 \\
0 & 0 & \gamma_{o} & \gamma_{1} & -\mu
\end{array}\right) .
$$

The eigenvalues obtained in (44) yield

$$
\left.\begin{array}{l}
-\mu, \\
m_{1}=-(\lambda+\mu), \\
m_{2}=-(\in+\mu+d) .
\end{array}\right\}
$$

The remaining characteristics polynomial is given by

$$
\lambda^{2}+\lambda\left(\mathrm{m}_{3}+\mathrm{m}_{4}\right)+\mathrm{m}_{3} \mathrm{~m}_{4}=0 .
$$

It is observed that (46) has strictly negative real root if and only if $m_{3}>0$ and $m_{4}>0$, and $m_{3}>m_{4}$. Also, $m_{3}$ is positive and for $\mathrm{m}_{4}$ to be positive, $1-R_{r}$ must be positive which leads to $R_{r}<1$. Therefore, the disease-free equilibrium $E_{o}$ (33) of model (8) is locally asymptotically stable if $R_{r}<1$.

\subsection{Global stability of disease-free equilibrium}

Theorem: The disease free equilibrium solution $E_{o}$ (33) of model system (8) is globally asymptotically stable whenever $R_{r}<1$.

Proof: A Lyapunov function is derived for the model system such that 


$$
\mathrm{F}=\left(\frac{\epsilon m_{4}+\sigma}{m_{2} m_{3}}\right) \mathrm{E}+\left(\frac{m_{4}+\sigma}{m_{3}}\right) I_{u}+\mathrm{I}_{\mathrm{v}}
$$

Where

$$
\dot{F}=\left(\frac{\epsilon m_{4}+\sigma}{m_{2} m_{3}}\right) \frac{d E}{d t}+\left(\frac{\mathrm{m}_{4}+\sigma}{\mathrm{m}_{3}}\right) \frac{d I_{u}}{d t}+\frac{d I_{v}}{d t}
$$

and

$$
\begin{aligned}
\dot{F}= & \left(\frac{\epsilon m_{4}+\sigma}{m_{2} m_{3}}\right)\left(\beta S-m_{3} \mathrm{E}\right)+\left(\frac{\mathrm{m}_{4}+\sigma}{\mathrm{m}_{3}}\right) \\
& \left(\epsilon \mathrm{E}+m_{3} I_{u}\right)+\left(\sigma I_{u}-m_{4} I_{v}\right) .
\end{aligned}
$$

Since $\frac{A}{\mu}$ in (33), further simplification becomes

$$
\begin{gathered}
\dot{F} \leq\left(\frac{\epsilon m_{4}+\sigma}{m_{2} m_{3}}\right)\left(\frac{\beta A}{\mu}-m_{3} \mathrm{E}\right)+\left(\frac{m_{4}+\sigma}{m_{3}}\right) \\
\left(\epsilon \mathrm{E}+m_{3} I_{u}\right)+\left(\sigma I_{u}-m_{4} I_{v}\right)
\end{gathered}
$$

and

$$
\dot{F}=\frac{\lambda A \epsilon\left(\mathrm{m}_{4}+\sigma\right)}{\mu \mathrm{m}_{2} \mathrm{~m}_{3}}+\left(\sigma-\left(\mathrm{m}_{4}+\sigma\right)\right) I_{u}-\mathrm{m}_{4} I_{\mathrm{v}}
$$

Therefore

$$
\dot{F}=\mathrm{m}_{4}\left(R_{t r}-\frac{\lambda A \epsilon}{\mu \mathrm{m}_{2} \mathrm{~m}_{3}} I_{u}+I_{v}\right) .
$$

Since all the parameters and variables of the model system (8) are nonnegative, it follows that $F \leq 0$ for $R_{r}<$ 1 with $\dot{F}=0$ if and only if $E=I_{u}=I_{v}=0$. Hence, $\dot{F}$ is a Lyapunov function in $\Omega$. Therefore, the largest compact invariant subset of the set where $\dot{F}=0$ is the singleton $\left\{\left(E, I_{u}, I_{v}\right)=(0,0,0)\right\}$. Thus, it follows, from the La-Salle's invariant principle [19], that as $t \rightarrow \infty$,

$$
\left(E, I_{u}, I_{v}\right) \rightarrow(0,0,0) .
$$

Therefore the disease-free equilibrium (33), of model (8) is globally asymptotically stable if $R_{t r}<1$.

\subsection{Global stability of endemic equilibrium}

Theorem: If $R_{r}>1$, the endemic equilibrium solution (34) of the model system (8) is globally asymptotically stable.

Proof: A Lyapunov function candidate of the form

$$
\begin{aligned}
\mathrm{L}(\mathrm{t}) & =\left(\mathrm{S}-\mathrm{S}^{*}-\mathrm{S}^{*} \log \mathrm{e} \frac{S}{\mathrm{~S}^{*}}\right) \\
& +\left(\mathrm{E}-\mathrm{E}^{*}-\mathrm{E}^{*} \log \mathrm{e} \frac{E}{\mathrm{E}^{*}}\right) \\
& +\left(I_{u}-I_{u}^{*}-\log e \frac{I_{u}}{I_{u}^{*}}\right) \\
& +\left(I_{\mathrm{v}}-I_{v}^{*}-I_{v}^{*} \operatorname{Loge} \frac{I_{v}}{I_{v}^{*}}\right) \\
& +\left(\mathrm{R}-\mathrm{R}^{*}-\mathrm{R}^{*} \operatorname{Loge} \frac{R}{\mathrm{R}^{*}}\right)
\end{aligned}
$$

is derived, such that the time derivative of (54) becomes

$$
\begin{aligned}
\frac{d L}{d t}= & \left(\frac{S-S^{*}}{S}\right) \frac{d S}{d t}+\left(\frac{E-E^{*}}{E}\right) \frac{d E}{d t} \\
& +\left(\frac{I_{u}-I_{u}{ }^{*}}{I_{u}}\right) \frac{d I_{u}}{d t}+\left(\frac{I_{v}-I_{v}{ }^{*}}{I_{v}}\right) \frac{d I_{v}}{d t} \\
& +\left(\frac{R-R^{*}}{R}\right) \frac{d R}{d t}
\end{aligned}
$$

so that

$$
\begin{aligned}
\frac{d L}{d t}= & \left(\frac{S-S^{*}}{S}\right)\left(A-m_{1} S\right)+\left(\frac{E-E^{*}}{E}\right) \\
& \times\left(\lambda S-m_{2} E\right)+\left(\frac{I_{u}-I_{u}{ }^{*}}{I_{u}}\right)\left(\epsilon E-m_{3} I_{u}\right) \\
& +\left(\frac{I_{v}-I_{v}{ }^{*}}{I_{v}}\right)\left(\sigma I_{u}-m_{4} I_{v}\right)+\left(\frac{R-R^{*}}{R}\right) \\
& \times\left(\gamma_{o} I_{u}+\gamma_{1} I_{v}-\mu \mathrm{R}\right) .
\end{aligned}
$$

and

$$
\begin{aligned}
\frac{d L}{d t}= & \left(\frac{S-S^{*}}{S}\right)\left(A-m_{1}\left(S-S^{*}\right)\right)+\left(\frac{E-E^{*}}{E}\right) \\
& \times\left(\lambda\left(S-S^{*}\right)-m_{2}\left(E-E^{*}\right)\right)+\left(\frac{I_{u}-I_{u}{ }^{*}}{I_{u}}\right) \\
& \times\left(\epsilon\left(E-E^{*}\right)-m_{3}\left(I_{u}-I_{u}{ }^{*}\right)\right) \\
& \times\left(\frac{I_{v}-I_{v}{ }^{*}}{I_{v}}\right)-m_{4}+\left(\frac{R-R^{*}}{R}\right) \\
& \times\left(\gamma_{o}\left(I_{u}-I_{u}{ }^{*}\right)+\gamma_{1}\left(I_{v}-I_{v}{ }^{*}\right)-\mu\left(\mathrm{R}-\mathrm{R}^{*}\right)\right) .
\end{aligned}
$$

Further simplification of (57) yields 


$$
\begin{aligned}
\frac{d L}{d t}= & \left(\frac{\left(S-S^{*}\right)^{2}}{S}\right)\left(\frac{A}{\left(S-S^{*}\right)}-m_{1}\right) \\
& +\left(\frac{\left(E-E^{*}\right)^{2}}{E}\right)\left(\frac{\lambda\left(S-S^{*}\right)}{\left(E-E^{*}\right)}-m_{2}\right) \\
& +\left(\frac{\left(I_{u}-I_{u}{ }^{*}\right)^{2}}{I_{u}}\right)\left(\frac{\epsilon\left(E-E^{*}\right)}{\left(I_{u}-I_{u}^{*}\right)}-\mathrm{m}_{3}\right) \\
& +\left(\frac{\left(I_{v}-I_{v}\right)^{2}}{I_{v}}\right)\left(\frac{\sigma\left(I_{u}-I_{u}{ }^{*}\right)}{\left(I_{v}-I_{v}{ }^{*}\right)}-\mathrm{m}_{4}\right) \\
& +\left(\frac{\left(R-R^{*}\right)^{2}}{R}\right) \\
& \times\left(\frac{\gamma_{o}\left(I_{u}-I_{u}{ }^{*}\right)}{\left(R-R^{*}\right)}+\frac{\gamma_{1}\left(I_{v}-I_{v}{ }^{*}\right)}{\left(R-R^{*}\right)}-\mu\right)
\end{aligned}
$$

and

$$
\begin{aligned}
\frac{d L}{d t}= & \frac{A\left(S-S^{*}\right)}{S}+\frac{\lambda\left(S-S^{*}\right)\left(E-E^{*}\right)}{E} \\
& +\frac{\epsilon\left(E-E^{*}\right)\left(I_{u}-I_{u}{ }^{*}\right)}{I_{u}} \\
& +\frac{\sigma\left(I_{u}-I_{u}{ }^{*}\right)\left(I_{v}-I_{v}{ }^{*}\right)}{I_{v}} \\
& +\frac{\gamma_{o}\left(I_{u}-I_{u}{ }^{*}\right)\left(R-R^{*}\right)}{R} \\
& +\frac{\gamma_{1}\left(I_{v}-I_{v}{ }^{*}\right)\left(R-R^{*}\right)}{R} \\
& -\frac{m_{1}\left(S-S^{*}\right)^{2}}{S}-\frac{m_{2}\left(E-E^{*}\right)^{2}}{E} \\
& -\frac{\mathrm{m}_{3}\left(I_{u}-I_{u}{ }^{*}\right)^{2}}{I_{u}}-\frac{\mathrm{m}_{4}\left(I_{v}-I_{v}{ }^{*}\right)^{2}}{I_{v}} \\
& -\frac{\mu\left(R-R^{*}\right)^{2}}{R} .
\end{aligned}
$$

Hence, by collecting positive terms together and negative terms together in (59) becomes

$$
\frac{d L}{d t}=B_{1}-B_{2}
$$

Where

$$
\begin{aligned}
B_{1}= & \frac{A\left(S-S^{*}\right)}{S}+\frac{\lambda\left(S-S^{*}\right)\left(E-E^{*}\right)}{E} \\
& +\frac{\epsilon\left(E-E^{*}\right)\left(I_{u}-I_{u} *\right)}{I_{u}} \\
& +\frac{\sigma\left(I_{u}-I_{u}{ }^{*}\right)\left(I_{v}-I_{v}{ }^{*}\right)}{I_{v}} \\
& +\frac{\gamma_{o}\left(I_{u}-I_{u}{ }^{*}\right)\left(R-R^{*}\right)}{R} \\
& +\frac{\gamma_{1}\left(I_{v}-I_{v}{ }^{*}\right)\left(R-R^{*}\right)}{R}
\end{aligned}
$$

And

$$
\begin{aligned}
B_{2}= & \frac{m_{1}\left(S-S^{*}\right)^{2}}{S}+\frac{m_{2}\left(E-E^{*}\right)^{2}}{E} \\
& +\frac{m_{3}\left(I_{u}-I_{u}{ }^{*}\right)^{2}}{I_{u}}+\frac{m_{4}\left(I_{v}-I_{v}{ }^{*}\right)^{2}}{I_{v}} \\
& +\frac{\mu\left(R-R^{*}\right)^{2}}{R} .
\end{aligned}
$$

Thus if $B_{1}<B_{2}$, then $\frac{d L}{d t} \leq 0$. Note that, $\frac{d L}{d t}=0$ if and only if $\left(S=S^{*} E=E^{*}, I_{u}=I_{u}^{*}, I_{v}=I_{v}^{*}, R=R^{*}\right)$. Therefore, the largest compact, invariant set in $\left[\left(S^{*}, E^{*}\right.\right.$, $\left.\left.I_{u}^{*}, I_{V}^{*}, R^{*}\right) \in \Omega: \frac{d L}{d t}=0\right]$ is the singleton set $E^{* *}$, where $E^{* *}$ is the endemic equilibrium solution (34) of the model system (8). By La-Salle's invariant principle [20], $E^{* *}$ is globally asymptotically stable in $\Omega$ if $B_{1}<B_{2}$.

\subsection{Approximate solution of the SEIR epidemic model}

In this section, the approximate solution of the model system (8) is obtained, using the Runge-Kutta fourth order and DTM. The concept of DTM was first proposed by Zhou [28] for solving linear and nonlinear initial value problems in electrical circuit analysis. The method in many instances have been adopted to solve series of models based on differential equations. The concept of DTM is derived from the Taylor series expansion. This method requires that a system of differential equations together with its initial and boundary conditions are transformed into recurrent power series solutions.

Taylor series expansion of a function $f(x)$ about the point $x=0$ is given by

$$
f(x)=\sum_{n=1}^{\infty} \frac{1}{k !}\left(\mathrm{f}^{\mathrm{k}}(\mathrm{c})(\mathrm{x}-\mathrm{c})^{\mathrm{k}}\right)=0 .
$$

For all $x \in(c-r, c+r)$ such that $x=c$ converges to $f(x)$.

Definition 1: The differential transformation $F(k)$ of a function $f(x)$ is defined as

$$
F(k)=\frac{1}{k !}\left(\frac{d^{\mathrm{k}} f(x)}{d t^{k}}\right)_{k=0} .
$$

Definition 2: It follows from Eqs. (63) and (64) that the differential inverse transformation $\mathrm{f}(x)$ of $\mathrm{F}(\mathrm{k})$ is given by

$$
f(x)=\sum_{k=0}^{\infty} \frac{t^{k}}{k !} \frac{\mathrm{d}^{\mathrm{k}} \mathrm{f}(\mathrm{t})}{\mathrm{dt}_{\mathrm{x}=\mathrm{x}_{\mathrm{o}}}^{\mathrm{k}}} .
$$

Using (63)-(64), the following basic operations of DTM $[26,28]$ is tabulated below;

If $S(\mathrm{k}), E(\mathrm{k}), I_{u}(\mathrm{k}), I_{v}(\mathrm{k})$, and $R(\mathrm{k})$ denote the differential transformation of $S(\mathrm{t}), E(\mathrm{t}), I_{u}(\mathrm{t}), I_{\nu}(\mathrm{t})$, and $R(\mathrm{t})$ respectively, then the following recurrence relation of model system (8) are given by 


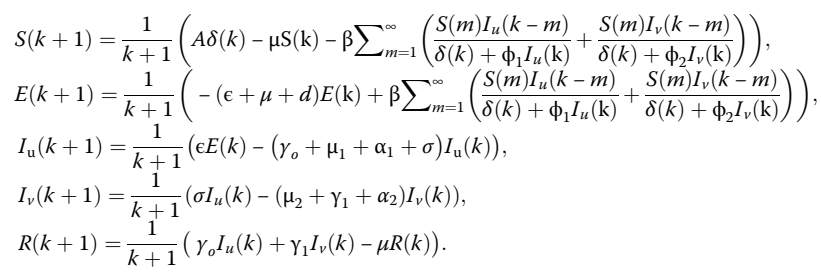

Applying the values of variables and parameters in Table 1 together with the initial conditions of the model, yields the following results given by

$$
\begin{aligned}
S(1) & =-17.768, E(1)=16.089, I_{u}(1) \\
& =-5.322, I_{v}(1)=27.500, R(1) \\
& =-2.162, S(2)=-10.330, E(2) \\
& =9.559, I_{u}(2)=1.496, I_{v}(2) \\
& =5.710, R(2)=1.513, S(3)=0.878, E(3) \\
& =0.778, I_{u}(3)=-0.252, I_{v}(3) \\
& =-1.591, R(3)=0.946 .
\end{aligned}
$$

Substituting the values in (67) into (66) yields, the recurrence relation given by the following;

Table 1 The meanings of variables and parameters of the SEIR model (8)

\begin{tabular}{lll}
\hline Symbols & Meanings of Variables and Parameters & Values \\
\hline$A$ & Recruitment rate of Humans & 0.781 day $^{-1}$ \\
$\beta$ & Disease transmission rate & 0.05 day $^{-1}$ \\
$\varphi_{1}$ & Emergence of disease symptoms in $I_{U}$ class $^{-1}$ & 0.312 day $^{-1}$ \\
$\varphi_{2}$ & Emergence of disease symptoms in $I_{V}$ class & 0.120 day $^{-1}$ \\
$\mu$ & Natural death rate & 0.002 day $^{-1}$ \\
$\epsilon$ & Transition rate from E to $I_{U}$ & 0.006 day $^{-1}$ \\
$d$ & Disease related death & 0.11 day $^{-1}$ \\
$\mu_{1}$ & Natural death in $I_{U}$ class & 0.0132 day $^{-1}$ \\
$\mu_{2}$ & Natural death in $I_{V}$ class & 0.0012 day $^{-1}$ \\
$a_{1}$ & Disease induced mortality in $I_{U}$ class & 0.12 day $^{-1}$ \\
$a_{2}$ & Disease induced mortality in $I_{V}$ class & 0.21 day $^{-1}$ \\
$\gamma_{1}$ & Recovery rate in $I_{U}$ class & 0.134 day $^{-1}$ \\
$V_{2}$ & Recovery rate in $I_{V}$ class & 0.123 day $^{-1}$ \\
$\sigma$ & Infectious transition from $I_{U}$ to $I_{V}$ & 0.3 day $^{-1}$ \\
$\theta$ & Modification parameter & 0.0021 day $^{-1}$ \\
$S$ & Susceptible Humans & 50 day $^{-1}$ \\
$E$ & Exposed Humans & 20 day $^{-1}$ \\
$I_{u}$ & Infected human who attend awareness & 10 day $^{-1}$ \\
$I_{V}$ & program & 7 day $^{-1}$ \\
& Infected human who did not attend & 3 day $^{-1}$ \\
\hline
\end{tabular}

$$
\begin{aligned}
& S(t)=\sum_{k=1}^{\infty} t^{k} S(k)=S(0)+t S(1)+t^{2} S(2)+t^{3} S(3)+\ldots, \\
& E(t)=\sum_{k=1}^{\infty} t^{k} E(k)=E(0)+t E(1)+t^{2} E(2)+t^{3} E(3)+\ldots, \\
& I_{u}(t)=\sum_{k=1}^{\infty} t^{k} I_{u}(k)=I_{u}(0)+t I_{u}(1)+t^{2} I_{u}(2)+t^{3} I_{u}(3)+\ldots, . \\
& I_{v}(t)=\sum_{k=1}^{\infty} t^{k} I_{v}(k)=I_{v}(0)+t I_{v}(1)+t^{2} I_{v}(2)+\hat{t}_{\nu}(3)+\ldots, \\
& R(t)=\sum_{k=1}^{\infty} t^{k} R(k)=R(0)+t R(1)+t^{2} R(2)+\hat{t}_{R}(3)+\ldots,
\end{aligned}
$$

The closed form solutions when $\mathrm{k}=3$, in (68) is given by

$$
\begin{aligned}
& S(t)=50-17.768 t-10.330 t^{2}+0.878 t^{3}+\ldots, \\
& E(t)=20+16.089 t+9.5585 t^{2}+0.778 t^{3}+\ldots, \\
& I_{u}(t)=10-5.322 t+1.496 t^{2}-0.252 t^{3}+\ldots, \\
& I_{v}(t)=7+27.500 t+5.710 t^{2}-1.591 t^{3}+\ldots, \\
& R(t)=3+2.162 t+1.513 t^{2}-0.946 t^{3}+\ldots
\end{aligned}
$$

Also, the idea of Runge-Kutta method was conceived by Carl Runge and Wilhem Kutta. This work employs the Runge-Kutta fourth-order method because of its accuracy and faster convergence, which have been employed to solve several problems in differential equations applied to science, engineering, economics etc. The numerical scheme for this method is given by

$$
y_{n+1}=y_{n}+\frac{1}{6}\left(z_{1}+2 z_{2}+2 z_{3}+z_{4}\right) .
$$

Where

$$
\left.\begin{array}{rl}
z_{1} & =h f\left(x_{n}, y_{n}\right), \\
z_{2} & =h f\left(x_{n}+\frac{1}{2} h, y_{n}+\frac{1}{2} z_{1}\right), \\
z_{3} & =h f\left(x_{n}+\frac{1}{2} h, y_{n}+\frac{1}{2} z_{2}\right), \\
z_{4} & =h f\left(x_{n}+h, y_{n}+z_{3}\right) .
\end{array}\right\}
$$

Applying the Runge-Kutta scheme to the model system (8) yields

$$
\left.\begin{array}{l}
S_{n+1}=S_{n}+\frac{1}{6}\left(q_{1}+2 q_{2}+2 q_{3}+q_{4}\right) h \\
E_{n+1}=E_{n}+\frac{1}{6}\left(y_{1}+2 y_{2}+2 y_{3}+y_{4}\right) h \\
I_{v n+1}=I_{v n}+\frac{1}{6}\left(x_{1}+2 x_{2}+2 x_{3}+x_{4}\right) h \\
I_{u n+1}=I_{v n}+\frac{1}{6}\left(u_{1}+2 u_{2}+2 u_{3}+u_{4}\right) h \\
R_{n+1}=R_{n}+\frac{1}{6}\left(v_{1}+2 v_{2}+2 v_{3}+v_{4}\right) h
\end{array}\right\}
$$

Where 
Table 2 Numerical results of the model system equations using Runge-Kutta method

\begin{tabular}{llllll}
\hline Time $(\mathbf{t})$ & $\mathbf{S}(\mathbf{t})$ & $\mathbf{E}(\mathbf{t})$ & $\boldsymbol{I}_{\boldsymbol{u}}(\mathbf{t})$ & $\boldsymbol{I}_{\boldsymbol{v}}(\mathbf{t})$ & $\mathbf{R}(\mathbf{t})$ \\
\hline 0 & 50 & 20 & 10 & 7 & 3 \\
0.2 & 46.3241401 & 23.38344467 & 8.99269207 & 7.023710128 & 3.47116912 \\
0.4 & 42.6482802 & 26.76688931 & 7.98538415 & 7.047420250 & 3.94233820 \\
0.6 & 38.9724204 & 30.15033400 & 6.97807623 & 7.071130380 & 4.41350730 \\
0.8 & 35.2965055 & 33.53377866 & 5.97078631 & 7.094840511 & 4.88407660 \\
1.0 & 31.6207006 & 36.91722233 & 4.96346038 & 7.118555066 & 5.35584500 \\
\hline
\end{tabular}

$$
\begin{aligned}
& q_{1}=A-\mu S_{n}-\beta\left(\frac{I_{u n}}{1+\phi_{1} I_{u n}}+\frac{\theta I_{v n}}{1+\phi_{2} I_{v n}}\right) S_{n}, \\
& y_{1}=\beta\left(\frac{I_{u n}}{1+\phi_{1} I_{u n}}+\frac{\theta I_{v n}}{1+\phi_{2} I_{v n}}\right) S_{n}-(\epsilon+\mu+d) E_{n}, \\
& x_{1}=\epsilon E_{n}-\left(\gamma_{o}+\mu_{1}+\alpha_{1}+\sigma_{1}\right) I_{u n}, \\
& u_{1}=\sigma I_{u n}-\left(\mu_{1}+\gamma_{1}+\alpha_{2}\right) I_{v n}, \\
& v_{1}=\gamma_{o} I_{u n}+\gamma_{1} I_{v n}-\mu R_{n} .
\end{aligned}
$$

Also,

and

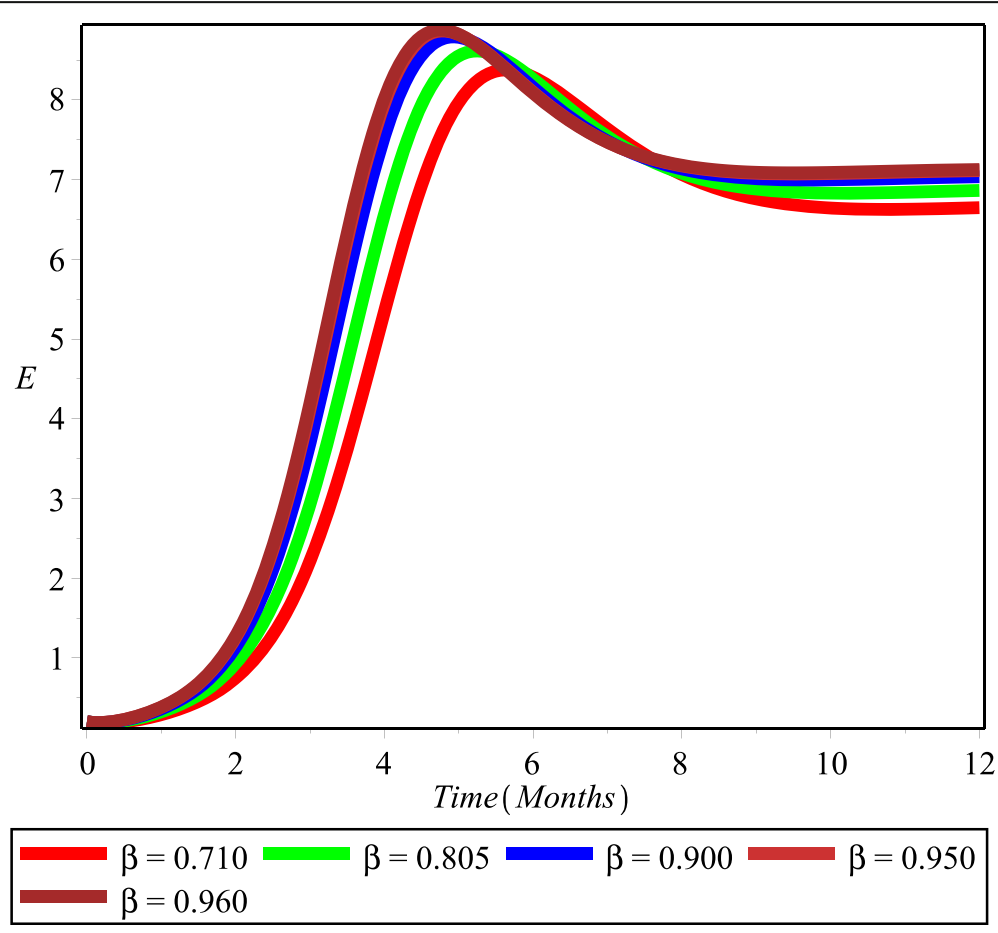

Fig. 1 Varying $\beta(0.001-0.027)$ when $R_{r}<1$ 


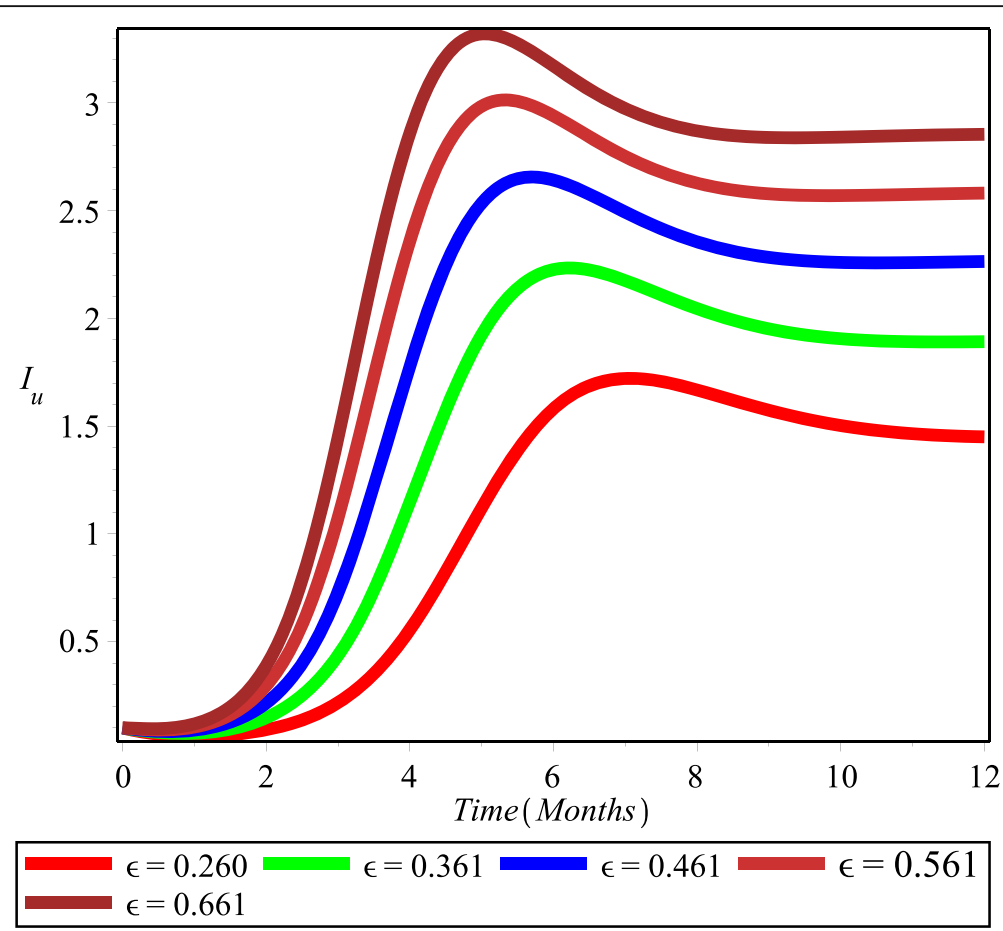

Fig. 2 Varying $\epsilon(0.001-0.0041)$ when $R_{r}<1$

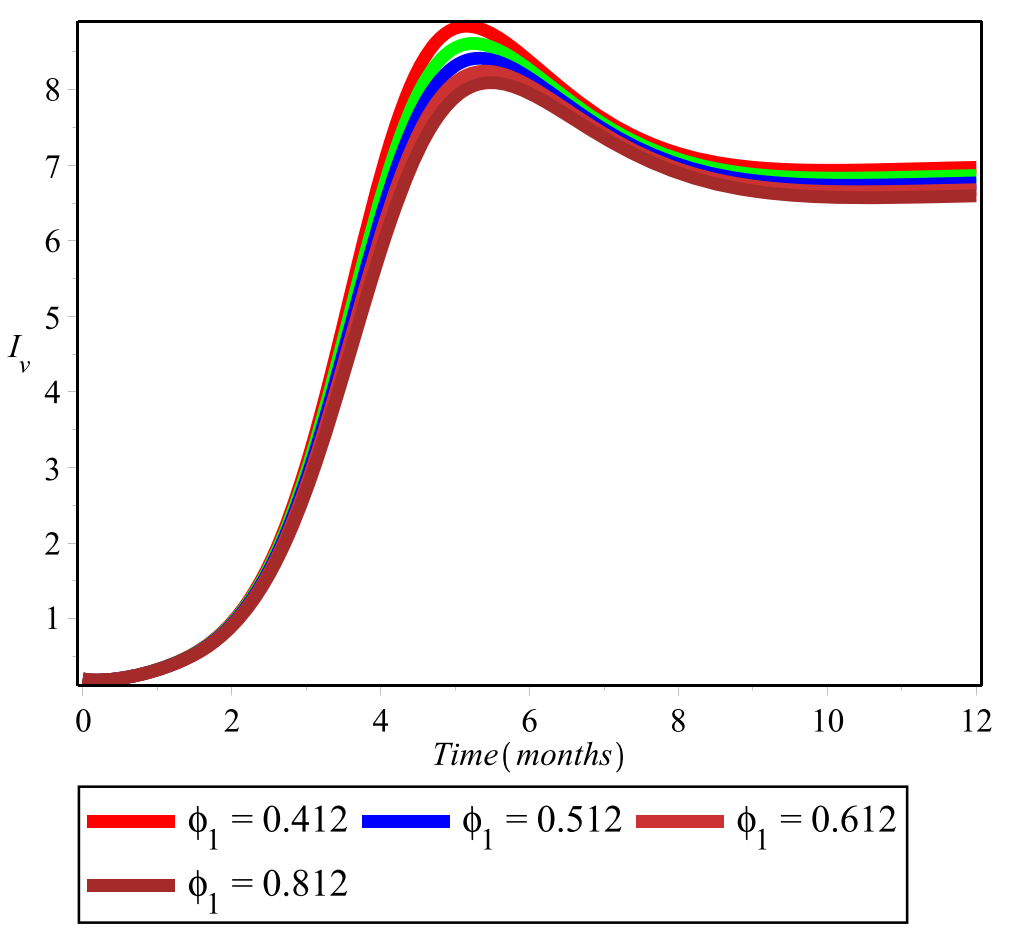

Fig. 3 Varying $\varphi_{1}(0.212-0.612)$ when $R_{r}<1$ 


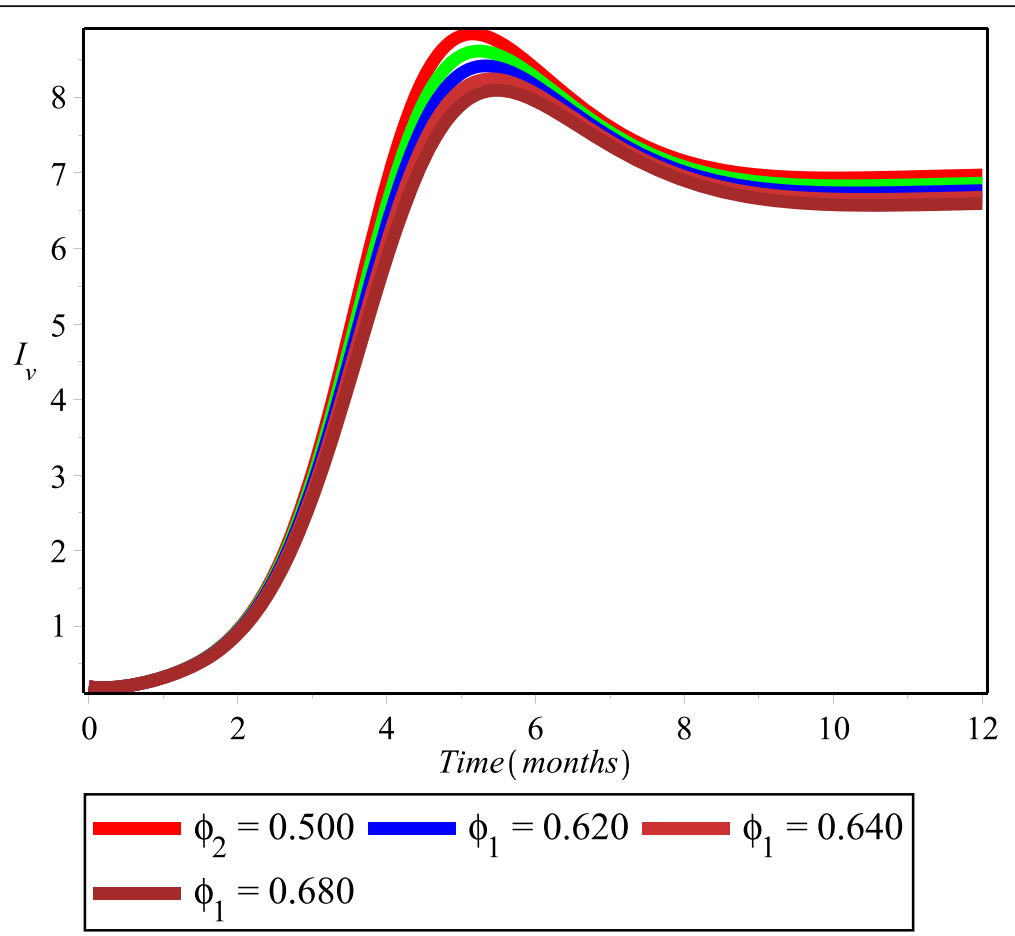

Fig. 4 Varying $\varphi_{2}(0.40-0.220)$ when $R_{r}<1$

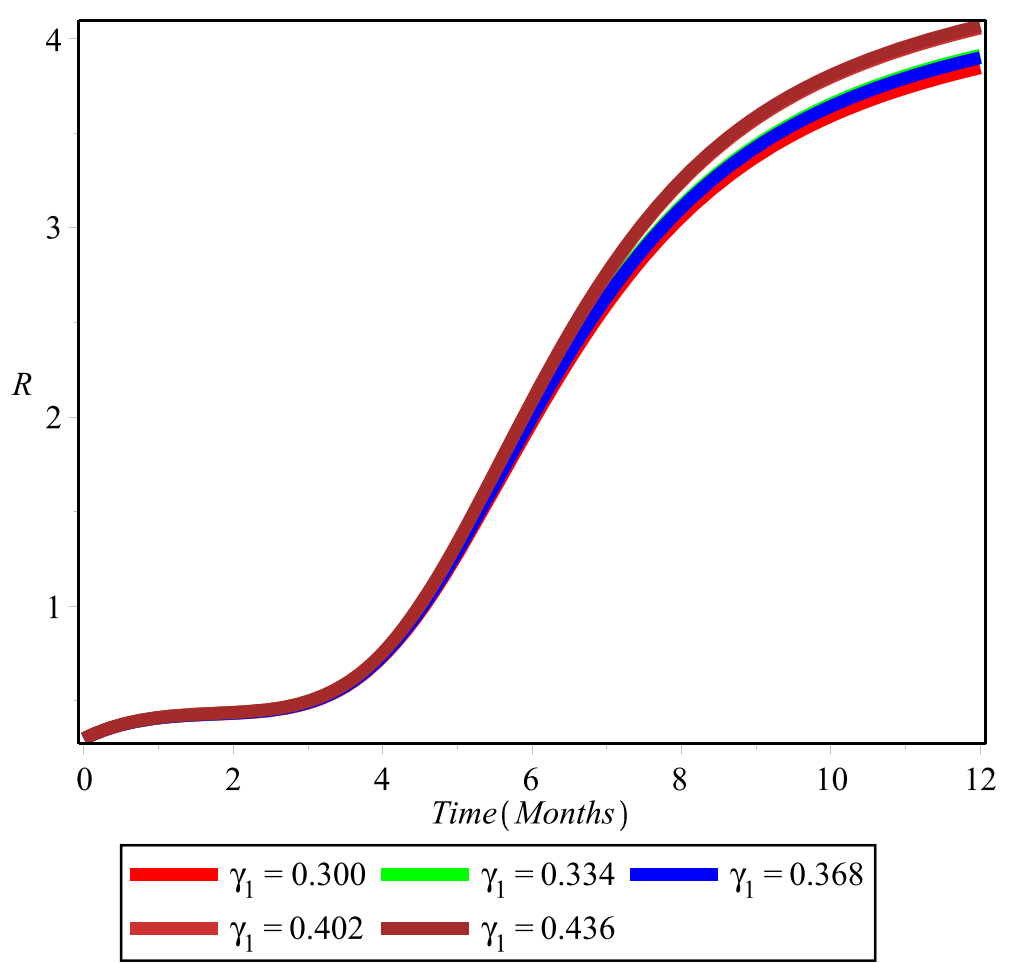

Fig. 5 Varying $\gamma_{o}(0.123-0.203)$ when $R_{r}<1$ 


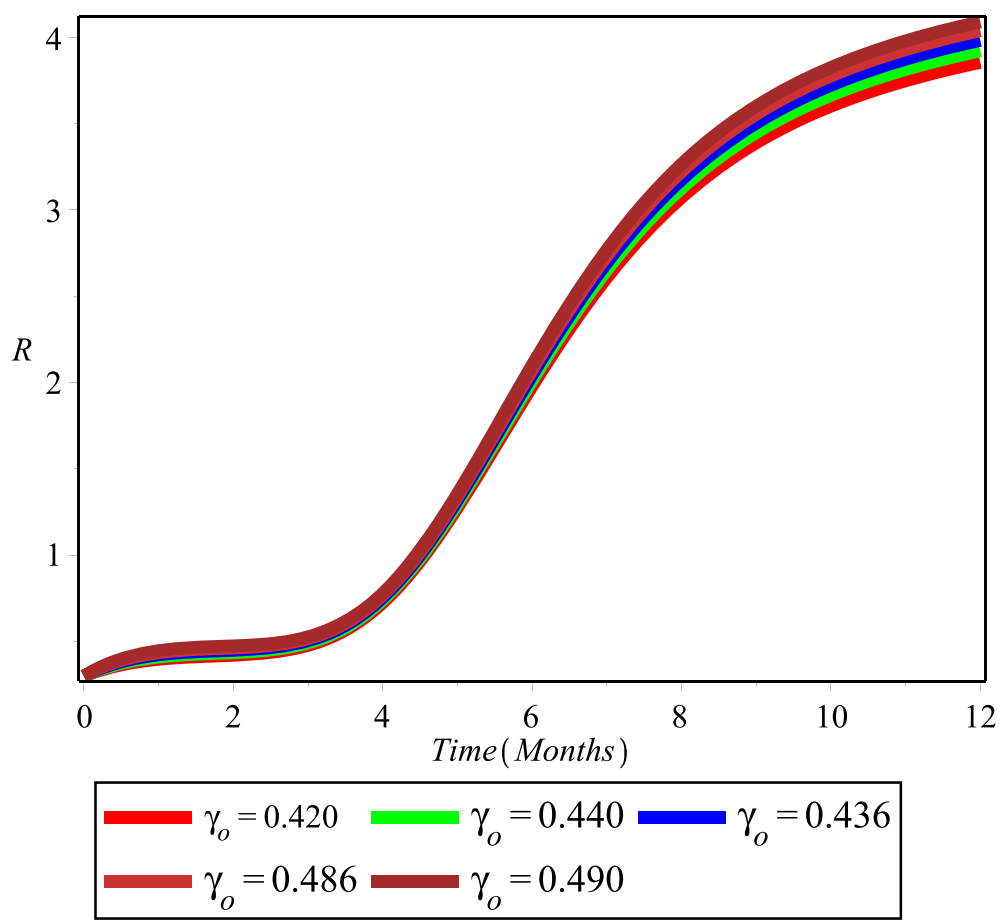

Fig. 6 Varying $\gamma_{1}(0.100-0.164)$ when $R_{r}<1$

$q_{3}=A-\mu\left(S_{n}+q_{2} \frac{h}{2}\right)-\beta\left(\frac{\left(I_{u n}+q_{2} \frac{h}{2}\right)}{1+\phi_{1}\left(I_{u n}+q_{2} \frac{h}{2}\right)}+\frac{\left(I_{v n}+q_{2} \theta \frac{h}{2}\right)}{1+\phi_{1}\left(I_{v n}+q_{2} \frac{h}{2}\right)}\right)$

$\left(S_{n}+q_{2} \frac{h}{2}\right)$,

$y_{3}=\beta\left(\frac{\left(I_{u n}+y_{2} \frac{h}{2}\right)}{1+\phi_{1}\left(I_{u n}+y_{2} \frac{h}{2}\right)}+\frac{\left(I_{v n}+y_{2} \theta \frac{h}{2}\right)}{1+\phi_{1}\left(I_{v n}+y_{2} \frac{h}{2}\right)}\right)\left(S_{n}+y_{2} \frac{h}{2}\right)$

$+(\epsilon+\mu+d)\left(E_{n}+y_{2} \frac{h}{2}\right)$,

$x_{3}=\epsilon\left(E_{n}+y_{2} \frac{h}{2}\right)+\left(\gamma_{o}+\mu_{1}+\alpha_{1}+\sigma\right)\left(\mathrm{I}_{\mathrm{un}}+x_{2} \frac{h}{2}\right)$,

$u_{3}=\sigma\left(I_{\text {un }}+x_{2} \frac{h}{2}\right)+\left(\gamma_{1}+\mu_{1}+\alpha_{2}\right)\left(\mathrm{I}_{\mathrm{vn}}+u_{2} \frac{h}{2}\right)$,

$v_{3}=\gamma_{o}\left(I_{u n}+x_{2} \frac{h}{2}\right)+\gamma_{1}\left(I_{v n}+u_{2} \frac{h}{2}\right)-\mu\left(R_{n}+v_{2} \frac{h}{2}\right)$,

And

$q_{4}=A-\mu\left(S_{n}+z_{3} h\right)-\beta\left(\frac{\left(I_{u n}+z_{3} h\right)}{1+\phi_{1}\left(I_{u n}+z_{3} h\right)}+\frac{\left(I_{u n}+z_{3} \theta h\right)}{1+\phi_{1}\left(I_{u n}+z_{3} h\right)}\right)$

$\left(S_{n}+z_{3} h\right)$,

$y_{4}=\beta\left(\frac{\left(I_{\text {un }}+z_{3} h\right)}{1+\phi_{1}\left(I_{\text {un }}+z_{3} h\right)}+\frac{\left(I_{\text {un }}+z_{3} \theta h\right)}{1+\phi_{1}\left(I_{\text {un }}+z_{3} h\right)}\right)$

$\left(S_{n}+z_{3} h\right)-(\epsilon+\mu+d)\left(E_{n}+y_{3} h\right)$,

$x_{4}=\epsilon\left(E_{n}+y_{3} h\right)-\left(\gamma_{o}+\mu_{1}+\alpha_{1}+\sigma_{1}\right)\left(I_{u n}+x_{3} h\right)$,

$u_{4}=\sigma\left(I_{u n}+x_{3} h\right)-\left(\mu_{1}+\gamma_{1}+\alpha_{2}\right)\left(I_{v n}+u_{3} h\right)$,

$v_{4}=\gamma_{o}\left(I_{u n}+x_{3} h\right)+\gamma_{1}\left(I_{v n}+u_{3} h\right)-\mu\left(R_{n}+v_{3} h\right)$.

Substituting (73) to (76), together with the parameter values and initial conditions of the model system (8) into (72) yield the numerical results in Table 2.

\subsection{Results}

Simulations are carried out by varying some parameters of the models when the basic reproduction number $R_{t r}<$ 1 as shown in Figs. 1, 2, 3, 4, 5, and 6, that is, the parameter solutions converges to the disease-free equilibrium. Tables 1 and 3 display the parameter and variable values used in the simulations of the model and the basic operations of DTM. Also, the numerical results of the model system is presented using Runge-Kutta fourth order and differential transform method (DTM) in Tables 2 and 4 which compare agreeably with each other, and the DTM performs better. Figure 1 is the description of the impact

Table 3 Basic Operations of DTM

\begin{tabular}{ll}
\hline Original function $\mathbf{f}(\mathbf{x})$ & Transformed function $\mathbf{F}(\mathbf{k})$ \\
\hline$f(x)=g(x) \pm h(x)$ & $F(k)=G(k) \pm H(k)$ \\
$f(x)=c g(x)$ & $F(k)=c G(k)$, where c is a constant \\
$f(x)=\frac{d g(x)}{d x}$ & $F(k)=(k+1) G(k+2)$ \\
$f(x)=\frac{d^{m} g(x)}{d x^{n}}$ & $F(k)=(k+1)(k+2) \ldots(k+m) G(k+m)$ \\
$f(x)=1$ & $F(k)=\delta(k)$ \\
$f(x)=x$ & $F(k)=\delta(k-1)$ \\
$f(x)=x^{m}$ & $F(k)=\delta(k-m)=\left\{\begin{array}{l}1, \text { if } k=m \\
0, \text { if } k \neq m\end{array}\right.$ \\
$f(x)=g(x) h(x)$ & $F(k)=\sum_{m=0}^{k} H(m) G(k-m)$ \\
$f(x)=e^{m x}$ & $F(k)=\frac{m^{k}}{k !}$ \\
$f(x)=(1+x)^{m}$ & $F(k)=\frac{m(m-1)(m-2) \ldots(m-k+1)}{k !}$ \\
\hline
\end{tabular}


Table 4 Numerical results of the model system equations using DTM

\begin{tabular}{llllll}
\hline Time $(\mathbf{t})$ & $\mathbf{S}(\mathbf{t})$ & $\mathbf{E}(\mathbf{t})$ & $\boldsymbol{I}_{\boldsymbol{u}}(\mathbf{t})$ & $\boldsymbol{I}_{\boldsymbol{v}}(\mathbf{t})$ & $\mathbf{R}$ \\
\hline 0 & 50 & 20 & 10 & 8 & 7 \\
0.2 & 46.0438184 & 23.59782685 & 8.99349350 & 7.741100 & 3.5004902 \\
0.4 & 42.2352922 & 26.87814813 & 8.09538109 & 7.811010 & 4.1674360 \\
0.6 & 38.7552644 & 30.57093498 & 7.29559566 & 7.211230 & 5.0462502 \\
0.8 & 35.9730239 & 33.98343857 & 5.58543315 & 7.843968 & 6.1823670 \\
1.0 & 31.5172160 & 36.08919010 & 4.95755349 & 7.619180 & 7.6211770 \\
\hline
\end{tabular}

of disease transmission rate $\beta$. As time increases, transmission of disease increases, but the steady decline, indicate that more humans are being aware of their disease status leading to quick movement to recovery state or probably death in the case of fatality. It is observed in Fig. 2 that there is a decrease of infection from the $1^{\text {st }}$ $6^{\text {th }}$ month as time increases, but a gradual rise of infection from the $7^{\text {th }}-12^{\text {th }}$ month depict that emergence of infection will be on the rise in the absence of health intervention policies. Figures 3 and 4 is the depiction of the high saturation of diseases in human host population as time increases. Strict compliance, increase of medical awareness programs, and treatment are needed to mitigate the high saturation of the disease in human host community, while Figs. 5 and 6 is the depiction of the impact of the variation of treatment rates $\gamma_{o}$ and $\gamma_{1}$ in infected humans. As time increases, a steady rise in the curve indicate that treatment is essential in minimizing infection in human host community.

In addition, simulations of variations of some increased parameter values displayed in Figs. 7, 8, 9, 10, 11 , and 12 reveal that the parameter solutions converges to the endemic state, that is, $R_{r}>1$. This implies that, for the system not to remain in the endemic state, transmission and new clinical manifestations of disease must be minimized by scaling up treatment and medical awareness program rate.

Figure 13 is the description of the sub-population of susceptible individuals who are at the risk of acquiring the disease. As time increases in the absence of control, more susceptible individuals become exposed to the disease. Figure 14 is the description of the sub-population of exposed individuals who are latently infected. As time increases, there is a quick inflow of exposed individuals

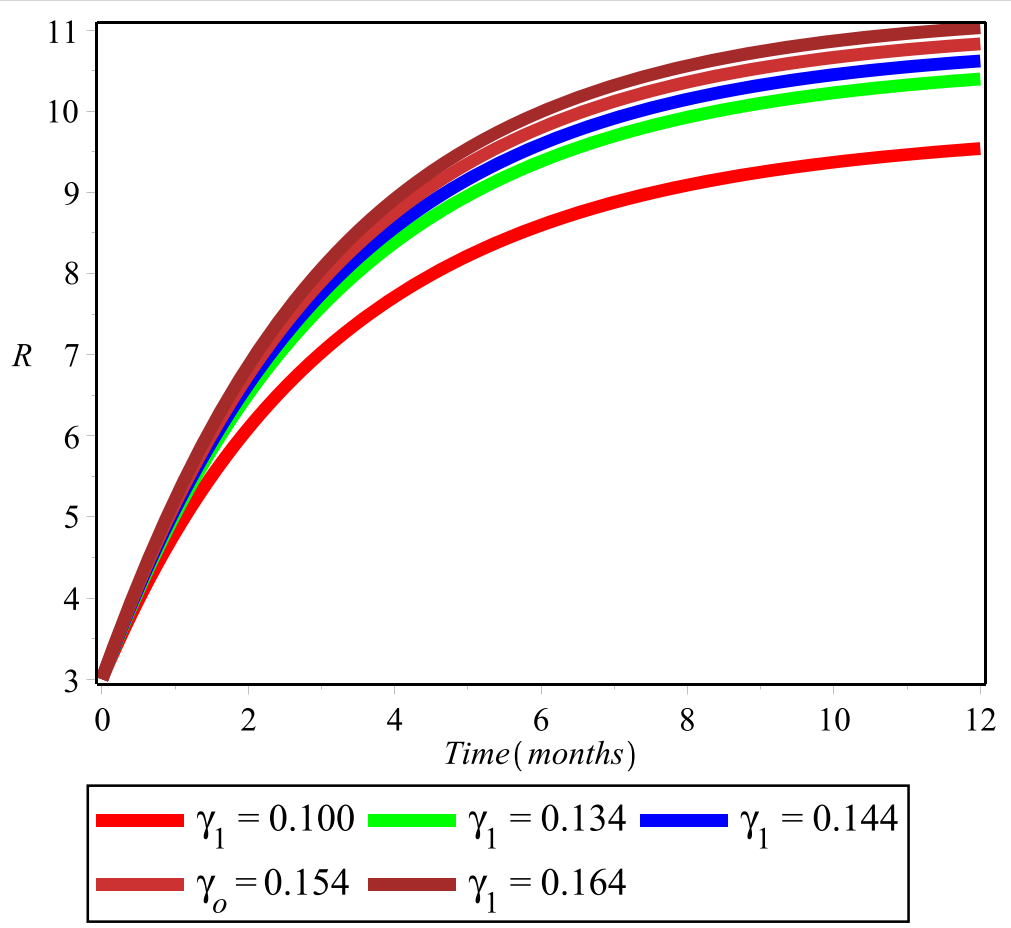

Fig. 7 Varying $\beta(0.710-0.960)$ when $R_{r}>1$ 


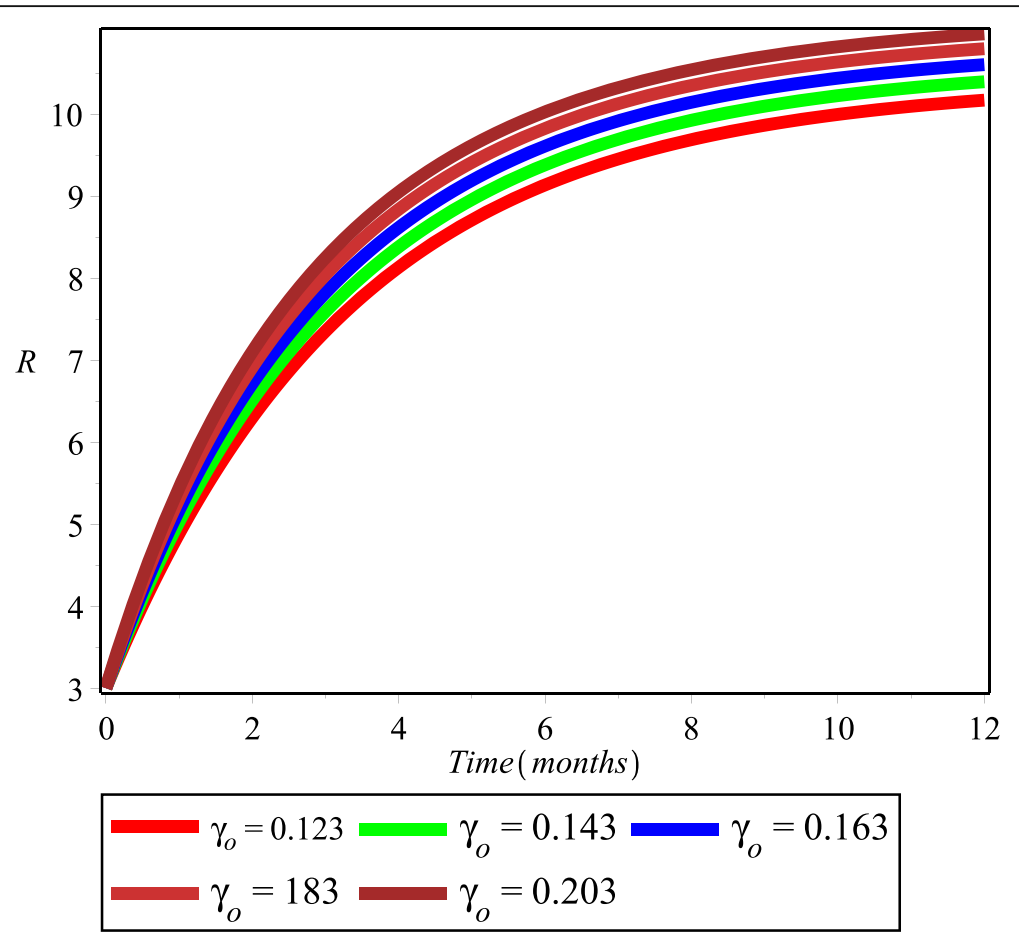

Fig. 8 Varying $\epsilon(0.260-0.661)$ when $R_{r}>1$

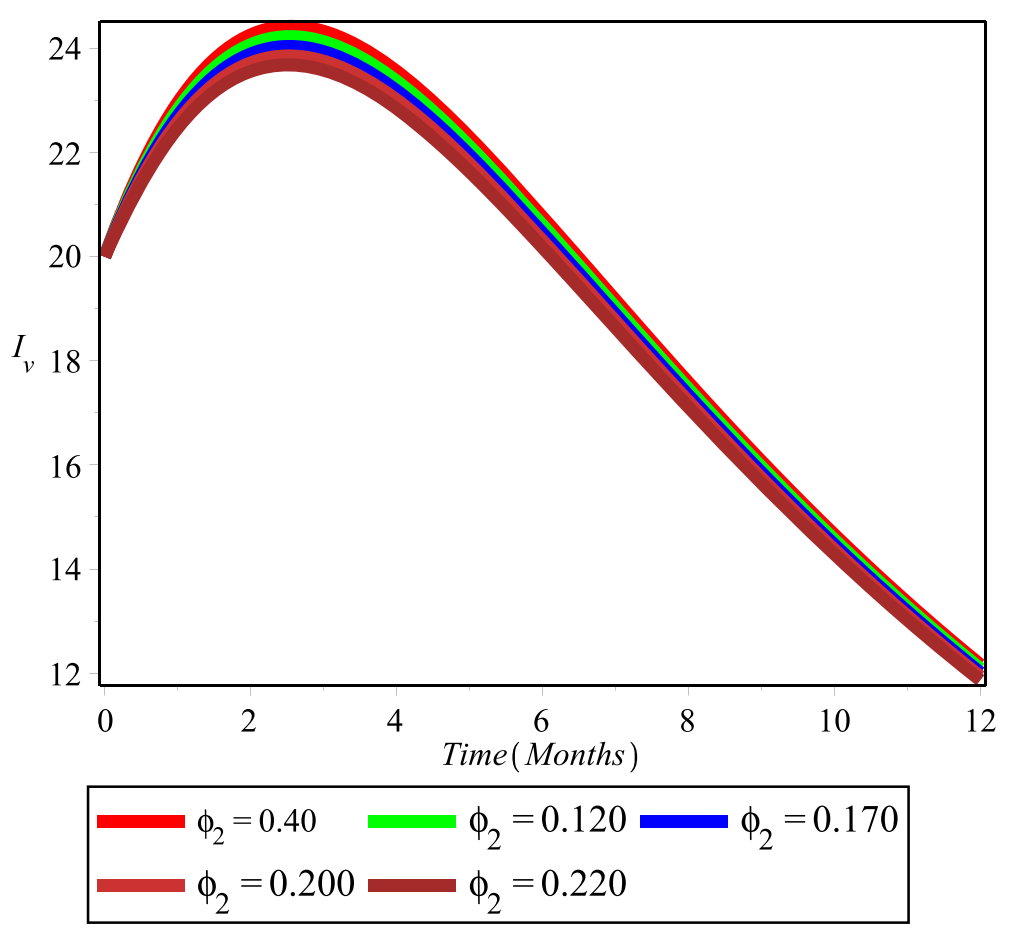

Fig. 9 Varying $\varphi_{1}(0.412-0.812)$ when $R_{r}>1$ 


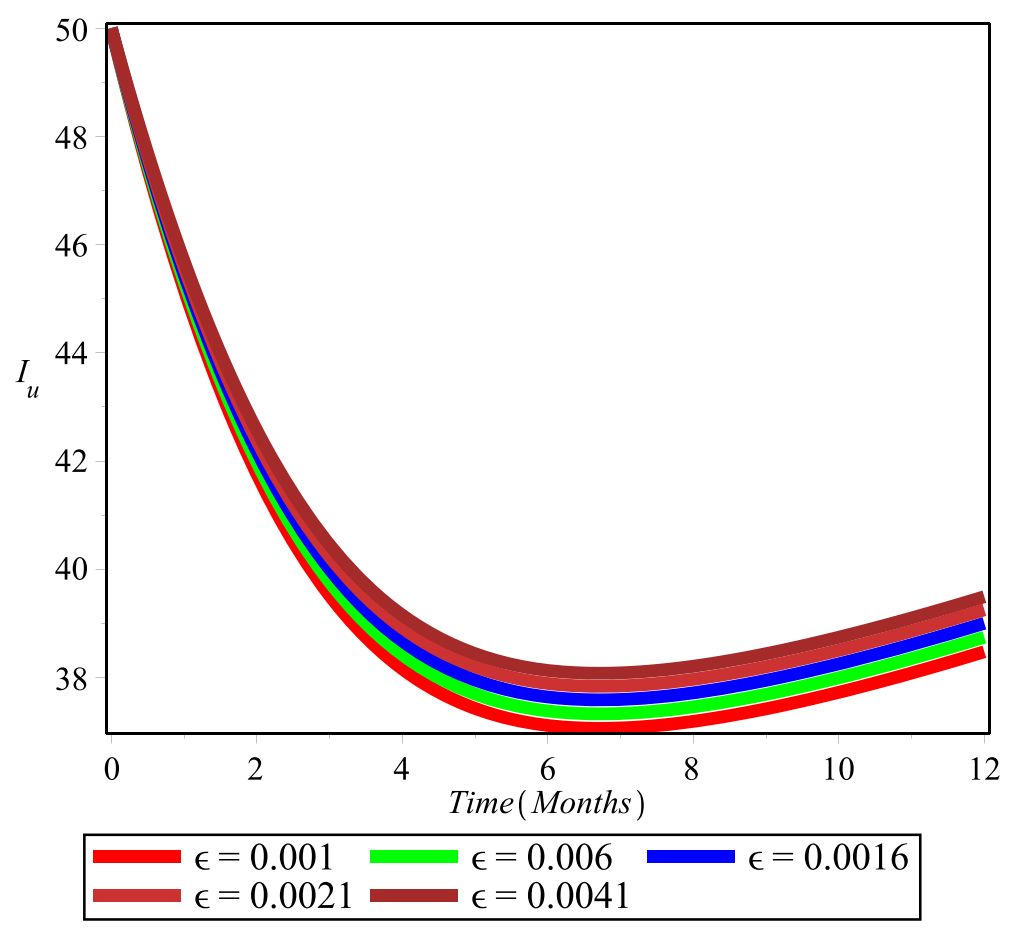

Fig. 10 Varying $\varphi_{2}(0.500-0.680)$ when $R_{r}>1$

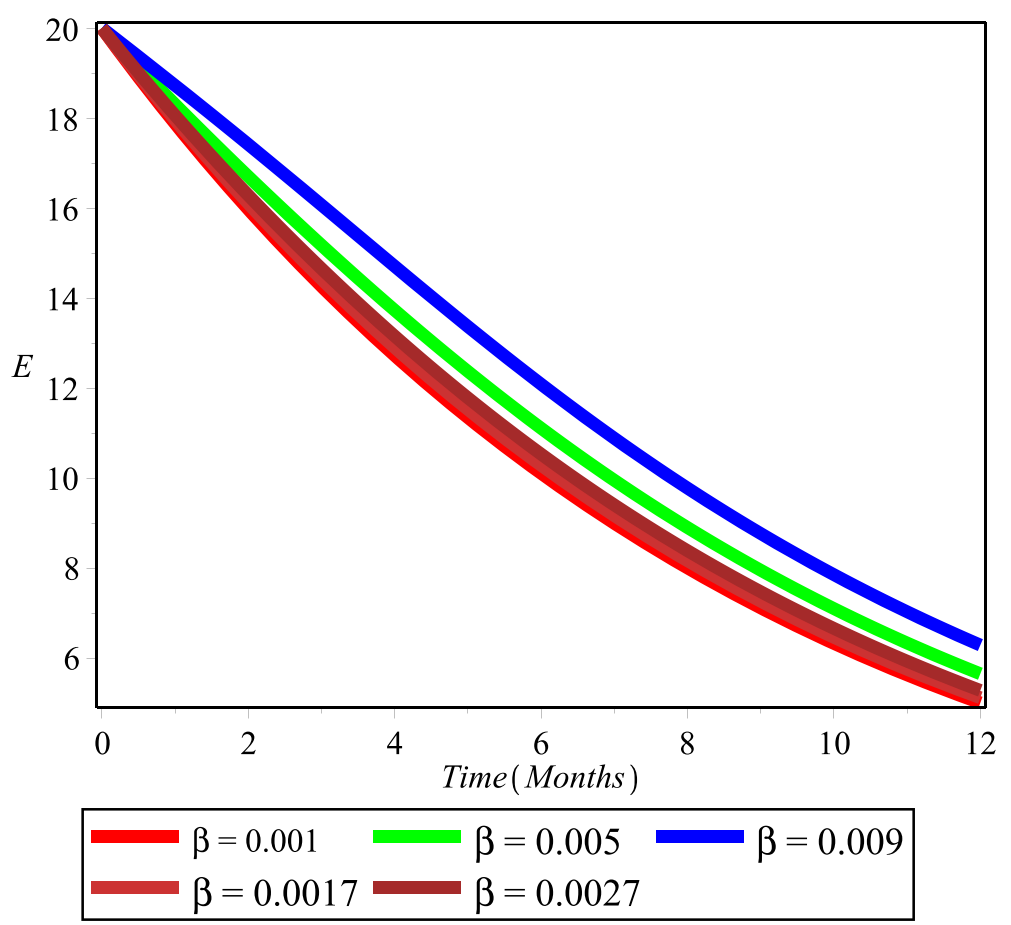

Fig. 11 Varying $\gamma_{1}(0.300-0.436)$ when $R_{r}>1$ 


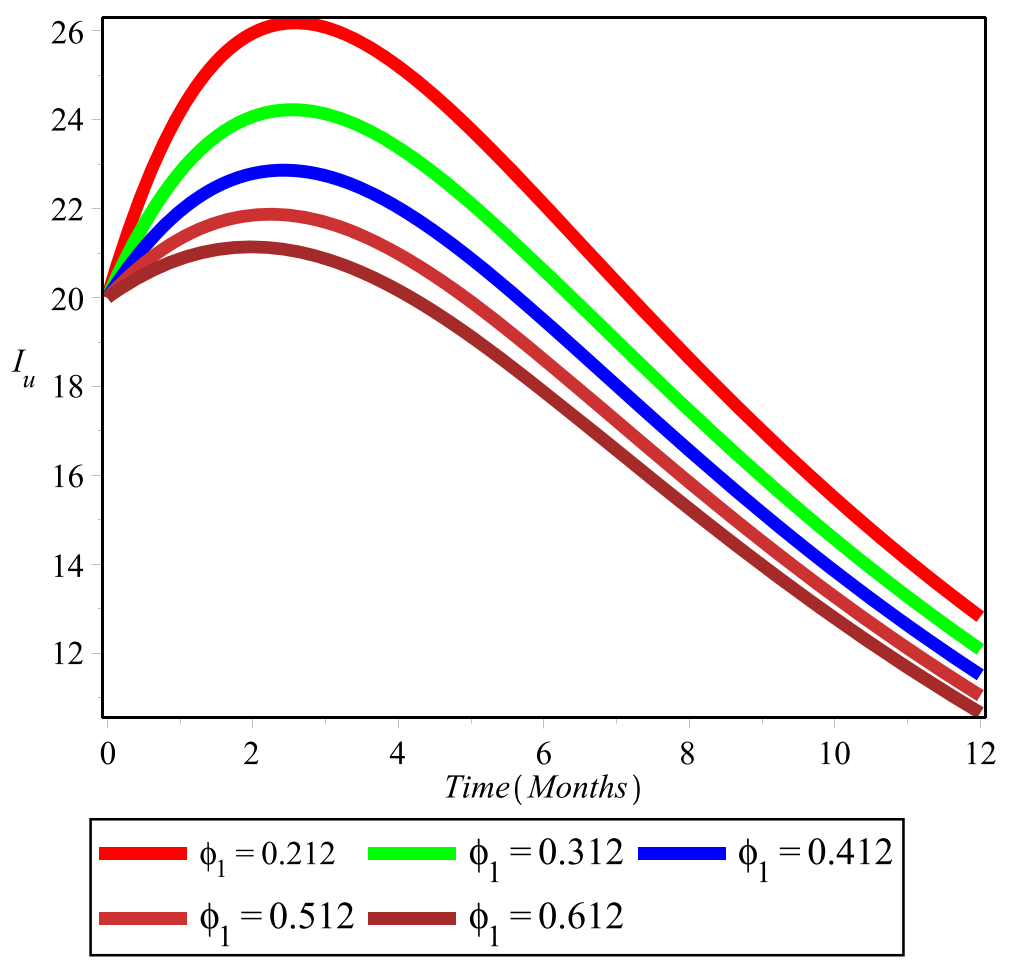

Fig. 12 Varying $\gamma_{o}(0.420-0.490)$ when $R_{r}>1$

moving into the infectious class. Figure 15 is the depiction of the behavior of sub-population of infected individuals who attend or are compliant to medical awareness program. As time increases, their compliance to medical awareness program leads to decrease of infected individuals as they are available to treatment, care, etc. Figure 16 is description of the behavior of the subpopulation of infected individuals who did not attend or are non-compliant to medical awareness program. As time increases, non compliance to medical awareness program results to fatal cases and probably death. Figure 17 is the description of the behavior of the recovered sub-population. Recovered humans increases as healthy measures are adopted by infected individuals leading to the reduction and elimination of the disease prevalence in human host community as time increases.

\section{Conclusion}

A generalized SEIR model describing the transmission of disease in human host community of infected individuals who attend or compliant and who did not attend (noncompliant) medical awareness program is established. Qualitative and quantitative mathematical techniques were used to analyze the invariant region and

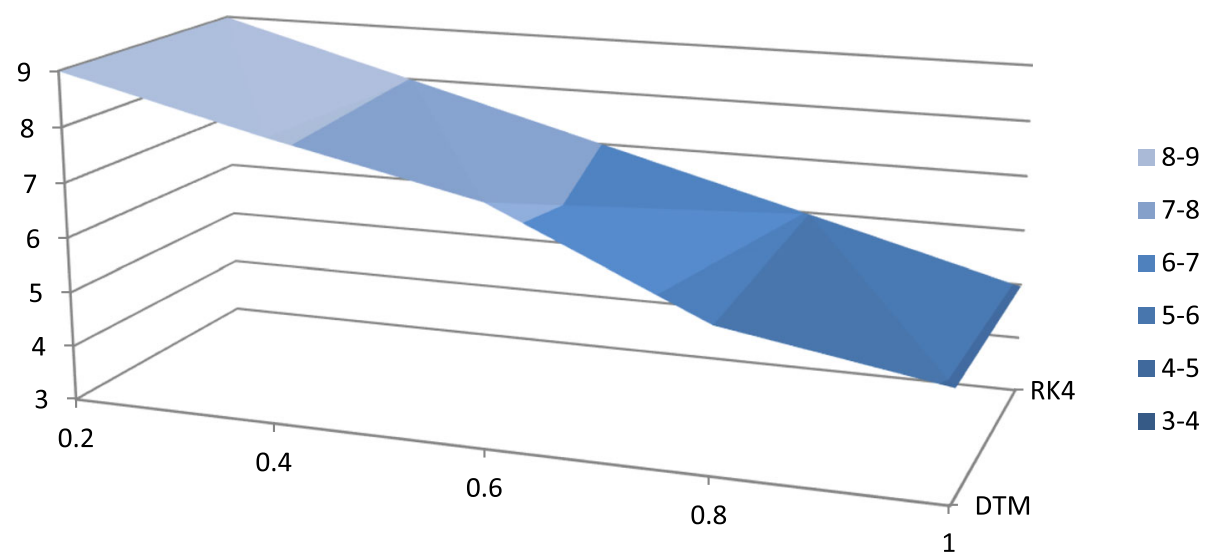

Fig. 13 Description of the sub-population of susceptible individuals who are at the risk of acquiring the disease 


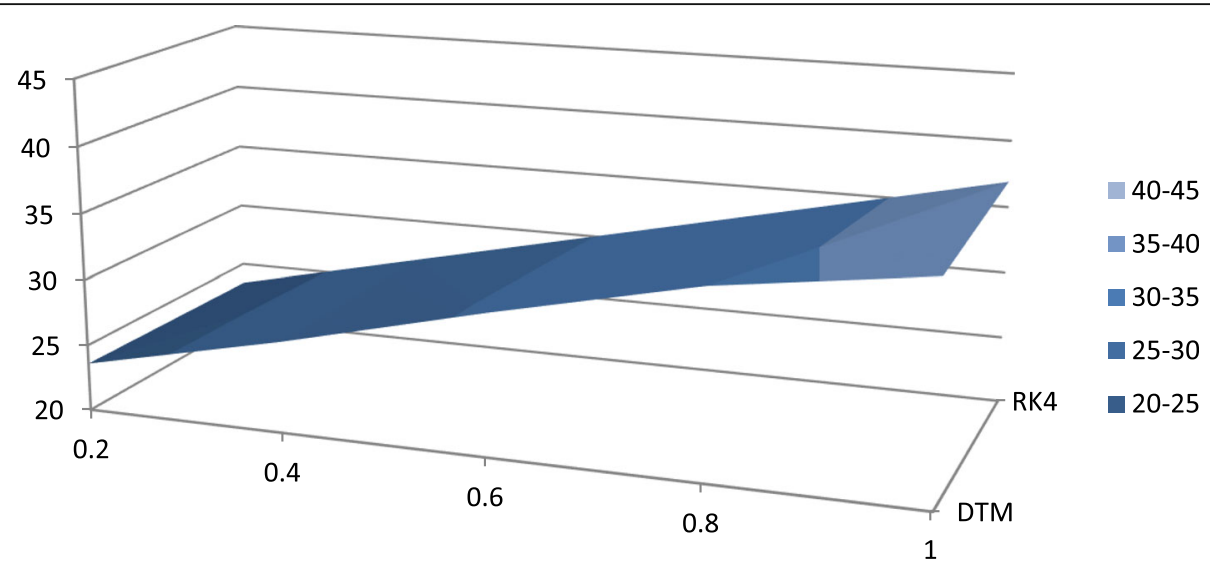

Fig. 14 Description of the sub-population of exposed individuals who are latently infected

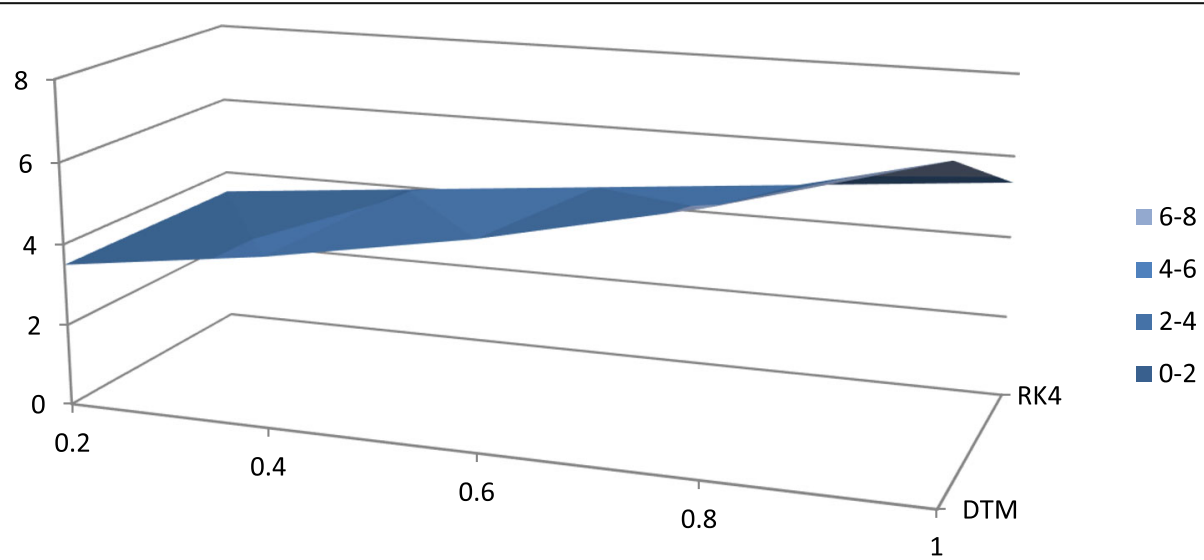

Fig. 15 Depiction of the behavior of sub-population of infected individuals who attend or are compliant to medical awareness program

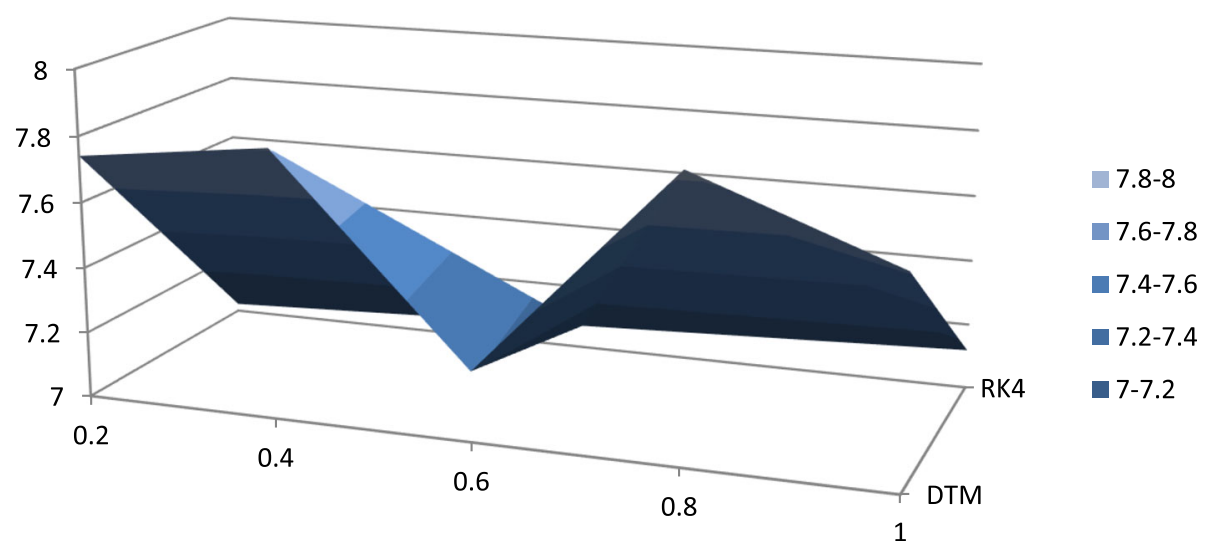

Fig. 16 Description of the behavior of the sub-population of infected individuals who did not attend or are non-compliant to medical awareness program 


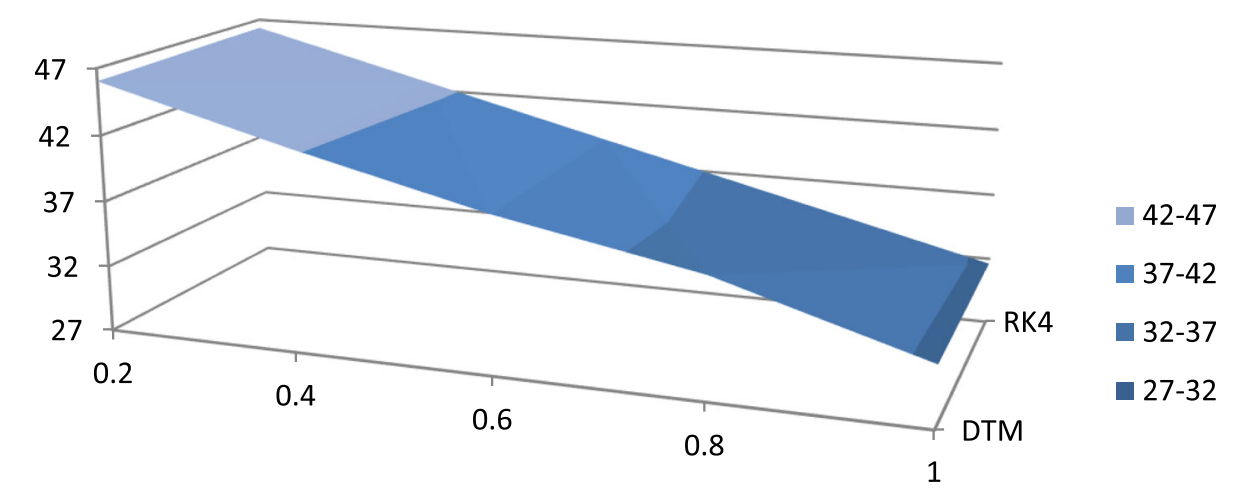

Fig. 17 Description of the behavior of the recovered sub-population

boundedness of the model. Also, the basic reproduction number $\left(R_{r}\right)$ and the equilibria is obtained to show that if $R_{r}<1$, the SEIR model disease-free equilibrium is locally and globally asymptotically stable and if $R_{r}>1$, the endemic equilibrium solution is globally asymptotically stable. Numerical methods of DTM and Runge-Kutta fourth-order method are employed to obtain the approximate solutions of the model as shown in Tables 2 and 4, which reveal that the two methods agree favorably with each other. Simulations of the model parameters when $R_{r}<1$ and $R_{r}>1$ is performed in Figs. 1, 2, 3, $4,5,6,7,8,9,10,11$ and 12 and the graphical behavior of the model in Figs. 13, 14, 15, 16 and 17 reveal that educational awareness about an epidemic breakout is essential in curbing the menace and endemicity of a disease. However, the limitation of this study is that the model cannot incorporate all the complexities involving human behavioral change toward compliance to medical awareness program and lack of real life data involving registration of human individuals that are medical awareness compliant or not in any endemic disease setting. To this end, this work is still recommended further for proper data fit to the model.

\section{Abbreviations}

SEIR: Susceptible - Exposed - Infected - Recovered; DTM: Differential Transform Method (DTM)

\section{Acknowledgement}

We acknowledge the effort of academic colleagues at the department of Mathematics, Faculty of Science, Ekiti state university, Ado-Ekiti, Nigeria.

\section{Authors' contributions}

OM reviewed and established the model as well as discussion of the numerical results, while $\mathrm{KH}$ performed the analysis and numerical computations of the work. All authors have read and approved the manuscript.

\section{Funding}

No funding have been received.

Availability of data and materials Not applicable.
Ethics approval and consent to participate

Not applicable.

Consent for publication

Not applicable.

\section{Competing interests}

There is no competing interest.

Received: 8 May 2020 Accepted: 8 January 2021

Published online: 10 March 2021

\section{References}

1. Kermack WO, Mckendrick AG (1927) A contribution to the mathematical theory of epidemics. Proc R Soc Lond 115:700-721 https://doi.org/10.1098/ rspa.1927.0118

2. Anderson RM, May RM (1991) Infectious disease of humans. Oxford University Press, London

3. Berreta E, Capasso V (1996) On the general structure of an epidemic system. Comp Math Appl 12:677-694

4. Idowu AS, Ogunmiloro OM (2020) Transmission dynamics of onhocerciasis with two classes of infections and saturated treatment function. Int J Model Simul Sci Comput 11(05):2050045 (24 pages) https://doi.org/10.1142/ S1793962320500476

5. Ogunmiloro OM, Idowu AS (2020) On the existence of invariant domain and local asymptotic behaviour of a delayed onchocerciasis model. Int J Mod Phys C 2050047:24 https://doi.org/10.1142/S0129183120501429

6. Ogunmiloro OM (2020) Stability analysis and optimal control of strategies of direct and indirect transmission dynamics of conjunctivitis. Math Meth Appl Sci:1-18 https://doi.org/10.1002/mma.6756

7. Ogunmiloro OM $(2019,2019)$ Local and global asymptotic behavior of malaria -filariasis co-infections in complaint and non-complaint susceptible pregnant women to antenatal medical programs in the tropics. e-J Anal Appl Math (1):31-54 https://doi.org/10.2478/ejaam-2019-0003

8. Ogunmiloro OM (2019) Mathematical modeling of the co-infection dynamics of malaria-toxoplasmosis in the tropics. Biomed Lett 56(2):139163 https://doi.org/10.2478/ejaam-2019-0003

9. Bahaa GM (2017) Fractional optimal control problem for variable-order differential system. Fract Calc Appl Anal 20(6):1447-1470 https:/doi.org/10. 1515/fca-2017-0076

10. Bahaa GM (2017) Fractional optimal control problem for differential system with delay argument. Adv Differ Equ 69(2017):1447-1470 https://doi.org/10. 1186/s13662-017-1121-6

11. Bahaa GM (2017) Fractional optimal control problem for variational inequalities with control constraints. IMA J Math Control Inf 35(1):107-122 https://doi.org/10.1093/imamci/dnw040

12. Fagbamigbe AF, Idemudia ES (2015) Barriers to antenatal care use in Nigeria: evidences rom non-users and implications for maternal health programming. BMC Pregnancy Child Birth 15(95) https://doi.org/10.1186/ s12884-015-0527-y 
13. Makinde AO, Odimegwu CO (2020) Compliance with disease surveillance and notification by private health providers in south west Nigeria. Pan Afr Med J 35:114 https://doi.org/10.11604/pamj.2020.35.114.21188

14. Diekmann O, Heesterbeek JAP, Roberts MG (2010) Construction of next generation matrices for compartmental epidemic models. J R Soc Biol Interface 7:873-885 https://doi.org/10.1098/rsif.2009.0386

15. Zhang J, Jia J (2014) Song X (2010) Analysis of an SEIR model with saturated incidence and saturated treatment. Sci World J 910421:11 https://doi.org/10. 1155/2014/910421

16. Alonso-Quesada S, De la Sen M, Nistal R (2018) On vaccination strategies for a SISV epidemic model guaranteeing the nonexistence of endemic solutions. Discret Dyn Nat Soc 20:9484121 https://doi.org/10.1155/2018/ 9484121

17. Chitnis N (2017) Introduction to SEIR models, workshop on mathematical models of climate variability, environmental change and infectious diseases, Trieste Italy May 8

18. Ganyani T (2018) Accessing inference of the basic reproduction number in an SIR model incorporating growth scaling parameter. Stat Med 37(29): 4490-45067 https://doi.org/10.1002/sim.7935

19. LaSalle J, Lifschetz S (1961) Sability of Lyapunov's direct method with applications. Academic, New York

20. Korobeinikov A (2004) Lyapunov functions and global properties for SEIR and SElS epidemic models. Math Med Biol 21:75-83 https:/doi.org/10.1093/ imammb21.2.75

21. He S, Peng Y, Sun K (2020) SEIR modeling of the COVID-19 and its dynamics. Nonlinear Dyn https://doi.org/10.1007/s11071-020-05743-y

22. Adebimpe O, Abiodun OE, Olubodun O, Gbadamosi B (2020) Dynamics and stability analysis of SEIRS model with saturated incidence rate and treatment. In: 2020 international conference in mathematics, computer engineering and computer science, ICMCECS 2020. Institute of Electrical and Electronics Engineers Inc https://doi.org/10.1109/ICMCECS47690.2020. 246987

23. Khan MA, Khan Y, Islam S (2018) Complex dynamics of an SEIR epidemic model with saturated incidence rate and treatment. Physica A Stat Mech Appl 493:210-227 https://doi.org/10.1016/j.physa.2017.10.038

24. Chowell G (2017) Fitting dynamic models to epidemic outbreak with quantified uncertainty, identifiability and forecasts. Infect Dis Model 2(3): 379-398 https://doi.org/10.1016/j.dm.2017.08.001

25. Side S, Utami AM, Surkana PMI (2018) Numerical solution of SIR model for transmission of tuberculosis by Runge - Kutta method. J Phys Conf Ser 1040:0122021 https://doi.org/10.1088/1742-6596/1040/1/012021

26. Ogunmiloro OM, Abedo FO, Kareem HA (2019) Numerical and stability analysis of the transmission dynamics of SVIR epidemic model with standard incidence rate. Malays J Comput 4(2):349-361 elSSN: 2600-8238 online

27. Tan D, Chen Z (2012) On a general formula for fourth order Runge-Kutta method. J Math Sci Math Educ 7(2):1-10

28. Zhou JK (1986) Differential transformation and its applications for Electrical Circuits (in Chinese). Huazhong University Press, Wuhan

\section{Publisher's Note}

Springer Nature remains neutral with regard to jurisdictional claims in published maps and institutional affiliations.

\section{Submit your manuscript to a SpringerOpen ${ }^{\circ}$ journal and benefit from:}

- Convenient online submission

- Rigorous peer review

- Open access: articles freely available online

- High visibility within the field

- Retaining the copyright to your article

Submit your next manuscript at $\boldsymbol{\nabla}$ springeropen.com 